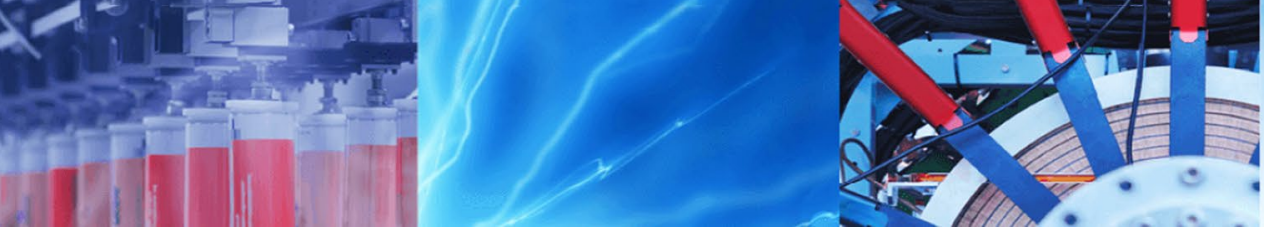

Research Article

\title{
Bio-climatic classification of Iran by multivariate statistical methods
}

\author{
Rasool Khatibi ${ }^{1} \cdot$ Morteza Saberi $^{1}$
}

Received: 23 June 2020 / Accepted: 5 August 2020 / Published online: 13 September 2020

(c) Springer Nature Switzerland AG 2020

\begin{abstract}
Traditional classification approaches tend to classify climates in terms of one or a few climatic variables given the specific circumstances. However, climate incorporates wide varieties of variables and serves as a cumulative process. In the present research, the number of 197 climatic parameters were selected and evaluated drawing upon data from the Iranian Meteorological Organization at 164 selected stations during the period of 1981 to 2018 . After accuracy verification (by statistics of reliable synoptic stations in the area), such parameters were applied to develop a database. Then, upon reviewing of the library documents while considering the effective climatic elements in the formation and distribution of vegetation in different regions of Iran, finally 137 climatic variables were identified, in turn used as input data to perform factor analysis in SPSS software. Such variables greatly affect the climate of each region, and in fact, are determinant factors of the climate in each area. Subsequently, cluster analysis was performed on climatic factors obtained from the factor analysis method. According to the results, throughout the Iran, nine factors of temperature, relative humidity, cold season rainfall, warm-season rainfall, wind speed, semi-cloudy days, thunderstorm and snowy day with eigenvalues greater than one were $29.71,22.32,9.58,7.52,6.22,6.80,4.25,3.69,2.22 \%$, respectively and totally accounted for $92.35 \%$ of the variance the data. Cluster analysis was an important step in determining the number of homogeneous clusters in this study. For this, the wards method was applied. First, by GIS software, the whole of Iran was divided into two climatic zones, and the climatic factors separating Iran into two zones were identified. Then two areas were divided into three sub-areas and this was continued until the final stage and at each stage, the factors separating the climatic zones were identified. By the final stage, it means stage at which the number of suitable and final zones is obtained. Subsequently, we reached from the climatic zone of 25 to zone of 26 , so that all suitable climate zones of Iran were obtained by cluster analysis. While we proceeded from the zoning phase of 26 to 27 and up, it had no effect on climate factors, and no factor was identified as a separating factor of climatic zones. Eventually, based on the multivariate statistical methods, 26 bioclimatic zones for Iran was obtained. Then, the overall vegetation map of Iran was networked by the kriging method and matched to the Iranian map of climatic zones. And exactly the dominant vegetation types were studied and introduced within each climatic zones. Finally, the results of the multivariate statistical method were compared with those of the traditional Pabout method and the weaknesses and strengths of the Pabout method and also multivariate statistical methods used in the bio-climatic zonation of Iran were investigated.
\end{abstract}

Keywords Bioclimatic classification · Cluster analysis · Climatic factors · Wards method · Geographical information system · Pabout classification

Rasool Khatibi, rasoolkhatibi@uoz.ac.ir; Morteza Saberi, m_saberi63@yahoo.com | 'Department of Soil and Water, Zabol University, Zabol, Iran.

SN Applied Sciences (2020) 2:1694 | https://doi.org/10.1007/s42452-020-03500-9 


\section{Introduction}

In a given area, the environmental potential depends on enormous factors. Such factors include climatic factors in turn along with land, water, and biological factors have great contributions in determining a region's environmental and economic development. Much attention has been paid to the climate in the environmental impact assessment of each region. The basic question in the early stages of evaluating the climatic potential of an area is whether climatic resources differ spatially and temporally? And also what is the exact nature of climatic resources? These stages of climatic classification determine the spatial characteristics of climatic resources. The main purpose of climatic classification is to determine geographical areas with similar climates or potentials. Climate has a very key and important role in the distribution of vegetation species [8]. Not surprisingly, such bioclimatic classifications across countries [31] denote the relationship between climatic patterns to vegetation species distribution across a country or in a limited area of a country [3,4]. Also, the purpose of bio-climatic classification is to link land uses to maintain priorities. [20] The prevailing assumption in these classifications is that climate is constant, although climate change is considered to be the result of human activity [10]. Climate change will affect the design and pattern of climate potential across countries, which not only affects the distribution of vegetation species and population levels They even influence management policies that protect vegetation species and their habitats [9]. Climate analysis methods based on computer models have been used rapidly and extensively over the past few decades [25] in global scale, the climate is typically the most important controller of vegetation species, and other factors, such as soil, topography, and human which have a smaller scale, are surely important, but are of secondary importance [22]. The climatic zonation of Pabout [19] is one of the initial efforts in the classification of Iran's bio climate. So that the bio climate of Iran was divided into three climates: Caspian climatic zone, Iran and Turani climatic zone, and Gulf-Omani zone. The criterion for Pabout classification is mainly rainfall, although, in the Caspian bio-climatic zone, altitude is also considered. Although the Pabout method has disadvantages, due to the lack of climatic information at the time of presentation, this system is valuable. But, since in this method, Iran's climatic zones are presented only on the basis of one climatic variable (annual rainfall), it has many major drawbacks and objections. The topic of bio-climates and the study of important climatic factors affecting vegetation is a very important issue, not only in Iran but throughout the world. So in this regard, Amigo and Ramirez [2] classified the bioclimatic classification in Chile, the climatic data of precipitation and temperature were taken from 140 meteorological stations, and finally the results of this study led to 4 climatic bioclimatic zones, which were: Tropical climate, Mediterranean climate, temperate climate and climate of northern area of Chile, also in the temperate climatic region, due to the climatic belt, the diversity of forest climax communities was discussed. Gavilan [6] used climatic parameters in vegetation, in this study, over 100 Phytoclimatic and climatic parameters were evaluated with using climate data recorded from 260 meteorological stations in an area called lber in Spain. Multivariate statistical methods and estimation analysis were used as statistical methods. The classification results showed different levels of correlation between climatic parameters. So that, 111 climatic parameters were divided into 5 larger groups. As expected, rainfall and temperature were variables that affecting the classification of vegetation cover area. Stiner [27] used 16 variable climate variables in 67 meteorological stations to analyze the United States by factor analysis. The results showed that 4 factors of humidity, weather disturbance, drought and temperature capability justifies $88.6 \%$ of the variance of the initial data. Martinez et al. [14] by multivariate statistical methods, determined of bioclimatic classification of Mexico City, for this study climatic data were extracted from 37 meteorological stations over a period of 30 years. The results showed that there are two large climatic regions in the region, which themselves are divided into four small climatic regions that had similar climatic characteristics. The most important climatic parameters which zoning was based on them were: temperature, rainfall, days with fog and frost, days with thunder storm, days with hail and freezing days. Zhou et al. [33] developed a climate map of Australia. In this study, spatial analysis techniques were used to create regional climate maps, which use climate variables to develop climatic zones: average annual rainfall, average annual evaporation and transpiration, annual average daily growth rate and average daily growth. The variables were obtained from 12 local meteorological stations for a period of 36 years from 1971 to 2006. Climatic data were used to analyze and evaluate regional climate variables by analyzing clusters in the GIS environment. Finally, GIS-dependent spatial analysis models are used to encapsulate sub-regional climatic maps from a set of climatic parameters derived from regional climatic data sources, which are two general climate patterns: based on the analysis, local clusters are presented in accordance with climatic variables. And another pattern includes (three comprehensive hydrothermal zones and six balanced hydrothermal zones). 
Gould et al. [7] explored the bioclimatic zone along the Canadian coast, showing the results of 5 sub-climatic zones in the study area. As in each of the following areas, the dominant vegetation cover was based on vegetative forms. In all 5 climatic zones, which were represented by the letters $A$ to $E$, the dominant vegetative forms were: $A$, pillows forbs, and $B$ : creeping shrubs and shrubs: And $C$ : shrubs and semi-creeping shrubs D: shrubs and erect shrubs E: shrubs, single shrubs with low density. Pesaresi et al. [21] in a study entitled "Italian bio-Climate" by using of worldclim data sources from climate data of temperature and precipitation with the Gis environment, prepared similar bio-climate maps and macro bioclimatic in Italy. The results show that these maps are useful as a set of raster data for purposes such as (1) identification of climatic regions of Italy (2) interactions between environmental-vegetation which used as modeling on national scales. Junior et al. [11] Applied Coupon Methods for Climatic zonation in Minas Gerias State of Brazil, finally, the results of climatic zoning were presented as a map.which on this map, climatic zones with acronyms $A, B, C$ were named, which were: A tropical rainfall climate $B$ : dry climate $C$ : temperate tropical climate. Hossell et al. [9] classified bio Climates of Britain and Ireland. In this study, 89 climate variables that have been of great climatic importance were studied by the method of basic components and cluster analysis. Finally, a map of the climatic zonation of Britain and Ireland by using of geographic information system is presented Also, the dominant species of each Zones, which are mainly tree species, have been introduced. Singh et al. [26] in research conducted to bioclimatic survey in northeastern India. They used meteorological data collected over a 30-year period for this classification, the data were collected from the Guwahati Meteorological Center and 30 meteorological stations in India. The results showed that the northeastern region of India was divided into three climatic zones: (a) hot and humid regions, (b) cold and humid, (c) cold and cloudy. This area is useful for a wide range of purposes, such as weather forecasting, building design, building energy protection, thermal comfort, and building design conditions. Netzel and Tomasz [18] on the application of cluster process for climatic classification, used 33 homogeneous clusters to create similar climate maps And compared by the koppen-Geiger classification method using theoretical information. The results showed that the best climatic zoning is done when 3 climatic variables (precipitation, temperature and maximum and minimum temperature) are used. And about half of the climates obtained using these variables corresponded to the koppen-Geiger method. And even the climatic zones obtained with these three climate variables are more homogeneous than the climatic zones obtained by koppen-Geiger method. Malmgren [13] analyzed climatic zoning in Puerto Rico based on the analysis of the principal components and the artificial neural network, and used climatic data of average seasonal and maximum rainfall, minimum temperature, and average temperature over a period of 30 years (1960-1990). The principal components Analysis and varimax rotation was used to reduce the data size. The results showed that the 5 main factors justify 0.9 changes. These factors are: mean minimum annual average temperature and average annual temperature, average annual maximum temperature, spring rainfall, summer rainfall, autumn rainfall. Finally, an artificial neural network algorithm was used to classify the scores of these five factors, which were obtained at the end of the four climatic zones. Wang et al. [29] in a study, conducted the northeastern climate of the United States. And with the aim of providing climatic data and providing comprehensive climate and historical information and climate change projects at an appropriate scale and easily accessible to researchers, they conducted this research. To do this, all climatic stations were used during the period 1901-2009, and variables such as daily growth temperature, number of annual frost days, drought index and maximum and temperature ambush were used. Rosati et al. [23] in a study entitled "bio-climate Map of Sardinia, Italy" by interpolation of technique and using temperature and rainfall variables prepared the bio-climate map of this region. Based on their results, two large bio-climates (Mediterranean and temperate oceans), one large semi-Mediterranean climate and four small continental climates, eight climatic horizons of thermal index (from the lowest warm Mediterranean civil climate) to the highest, seven embryonic climatic horizons (from minimum drought range to highest wetland) were identified. Martinez and Carbajal [15] in Climatic analysis linked to land vegetation cover of Mexico by applying multivariate statistical and clustering analysis showed that by applying two clustering criteria (K-means and Ward's method) it was possible to define statistically groups of stations that delimit regions of similar climate. They also showed that the analysis would help create new climate scenarios, and that the dynamics of vegetation cover could be considered as a climate indicator. Tsemma et al. [28] in a study, used a combination of a nonlinear model to estimate changes in leaf area index due to climate fluctuations along with a hydrological model of variable penetration capacity to improve river basin forecasting under climatic change conditions. The hybrid model was used for 13 different sub-basin with different uses with different terrestrial coverings (cultivation, tree and pasture). The results showed that during the drought period, there was a significant decrease of 
about $29.7 \%$ to $66.3 \%$ in the average annual runoff due to reduced rainfall and increased temperature. Also, when drought-related changes were included in the leaf area index, the average annual runoff forecast showed a smaller decrease (between 29.3 and 61.4\%). Xu [32] in a valuable study at the Yellow China Watershed in China, studied the dynamics of vegetation cover and plant response to climatic elements in the watershed from 1988 to 2008, with a cumulative approach from methods of involving correlation analysis, wave analysis, and wave regression analysis, the results showed that the correlation of vegetation with rainfall and temperature was significant and positive, but on the other hand, the correlation of vegetation with relative humidity and sunny hours was negative in some sites. Schmidt et al. [24] in a study entitled "The Relationship between Vegetation and Climate in the Tropical Areas of North Africa" studied the unilateral effect of weather on vegetation belonging to different classes. He showed that climate models provide consistent data without gaps in high spatial resolution. And a large and significant set of available climatic variables can be used as a perspective to transfer statistical relationships to future plans. They also showed that in addition to precipitation and temperature, other climatic variables such as solar radiation and relative humidity play an important role. Leilei et al. [12] In "The Relationship between Vegetation with Rainfall and Surface Temperature Based on Remote Sensing in Tibet, China" showed that Vegetation analysis under the influence of meteorological factors contribute to further research on the interaction of terrestrial ecosystems and climate change. And the results of this study showed that the average vegetation cover in August varies by about 0 to $99 \%$ depending on the location. And areas in southeastern Tibet receive between 600 and $800 \mathrm{~mm}$ of annual rainfall, while the western region of Tibet suffers from severe drought (less than $200 \mathrm{~mm}$ ). The results of this study also showed that the average temperature of the earth's surface in Tibet varies from -8.9 to $16.3^{\circ} \mathrm{C}$, and the correlation coefficient between the vegetation and rainfall index in September is the highest. And vegetation from April to October is more affected by rainfall than ground temperature. Past bio-climatic zoning in Iran [19] due to necessity and need, tended to separate the zones based on one or a small number of variables. While climate includes several variables and is the same size as a cumulative process. On the other hand, the basis for introducing the bio-climatic zones in Iran is the map of presented by Pabout in 1969 (Fig. 14). And all of researchers, especially university professors and students of natural resources and agriculture, refer to this old reference. While, unfortunately, Iran's bio-climatic areas with this source and reference have many problems, which are discussed in the discussion section. Therefore, our purpose in this study is to first examine the various climatic elements that are extracted from Iranian meteorological stations. And in the next step, the climatic factors affecting the distribution of the

Fig. 1 The study area

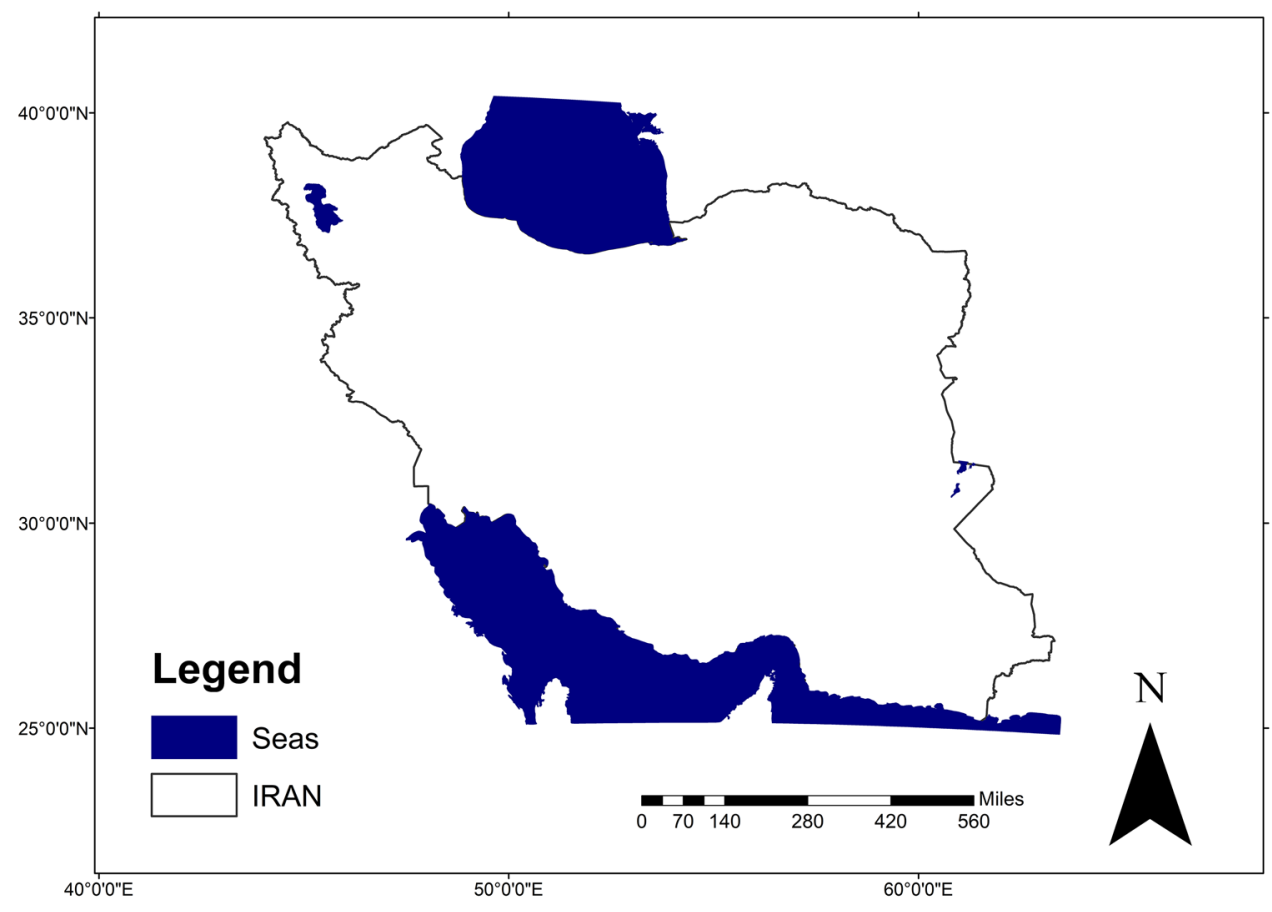

SN Applied Sciences 
dominant vegetation of Iran will be selected and the interaction between the primary variables will be performed by reducing the number of variables by factor analysis method. And determine the effect and appearance of each of the extraction factors in different locations (climatic zones). Then, by using the weight or score of each of the factors in different climatic zones and with cluster analysis (CA) method, divide these points into homogeneous regions and finally provide a precise zoning of bio-climatic classification in the whole country of Iran.

\section{Materials and methods}

\subsection{Study area}

This study was conducted throughout Iran. Having an area of $1,648,198 \mathrm{~km}^{2}$, Iran is a country of West Asia and in the Middle East, as well as Central Asia and the Caucasus,

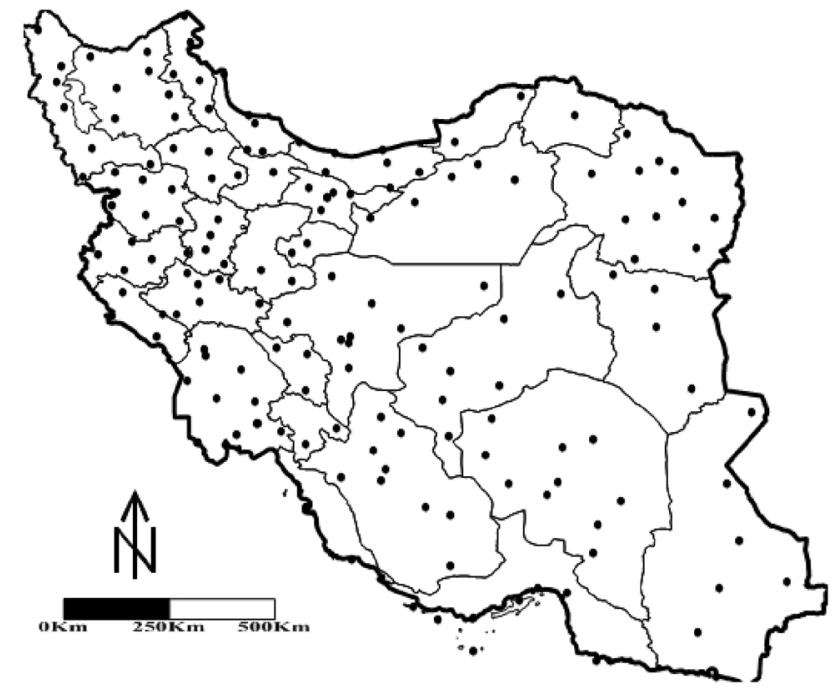

Fig. 2 Distribution of the studied climatic stations in this study
Table 1 Climatic variables used as input data for factor analysis

\begin{tabular}{|c|c|c|}
\hline Variable type (monthly and annual) & Unit & $\begin{array}{l}\text { Number of } \\
\text { variables }\end{array}$ \\
\hline The average of minimum temperature & ${ }^{\circ} \mathrm{C}$ & 7 \\
\hline Freezing days & daily & 4 \\
\hline The average of maximum temperature & ${ }^{\circ} \mathrm{C}$ & 9 \\
\hline The average of temperature & ${ }^{\circ} \mathrm{C}$ & 13 \\
\hline The average of relative humidity & Percent & 7 \\
\hline The average of maximum relative humidity & Percent & 7 \\
\hline The average of minimum relative humidity & Percent & 7 \\
\hline Monthly precipitation & $\mathrm{mm}$ & 13 \\
\hline Days with precipitation & $\mathrm{mm}$ & 13 \\
\hline Days with thunder storm & Daily & 6 \\
\hline Days with dust & Daily & 7 \\
\hline The average of wind speed & K note & 10 \\
\hline Days with partly cloudy & Daily & 8 \\
\hline Days with cloudy & Daily & 6 \\
\hline Sunshine & Hours & 9 \\
\hline Days with precipitation greater than or equal to 10 of winter season & $\mathrm{mm}$ & 1 \\
\hline Days with precipitation greater than or equal to 10 of spring season & $\mathrm{mm}$ & 1 \\
\hline Days with precipitation greater than or equal to 10 of summer season & $\mathrm{mm}$ & 1 \\
\hline Days with precipitation greater than or equal to 10 of fall season & $\mathrm{mm}$ & 1 \\
\hline Days with snow of winter season & $\mathrm{mm}$ & 1 \\
\hline Days with snow of spring seaso & $\mathrm{mm}$ & 1 \\
\hline Days with snow of summer season & $\mathrm{mm}$ & 1 \\
\hline Days with snow of fall season & $\mathrm{mm}$ & 1 \\
\hline Days with precipitation greater than or equal to 5 of winter season & $\mathrm{mm}$ & 1 \\
\hline Days with precipitation greater than or equal to 5 of spring season & $\mathrm{mm}$ & 1 \\
\hline Days with precipitation greater than or equal to 5 of summer season & $\mathrm{mm}$ & 1 \\
\hline Days with precipitation greater than or equal to 5 of fall season & $\mathrm{mm}$ & 1 \\
\hline Totals & & 137 \\
\hline
\end{tabular}


coordinates 25 and 39 and $47 \mathrm{E}$ and 44 and $6318 \mathrm{~N}$. Iran borders Armenia, Azerbaijan (including the Republic of Nakhichevan) and Turkmenistan in the north, Afghanistan and Pakistan in the east, and Iraq and Turkey in the west. In addition, Iran has a blue border in the Persian Gulf with Kuwait, Iraq, Saudi Arabia, Bahrain, Oman, Qatar, and the United Arab Emirates (Fig. 1).

\subsection{Methods}

In The present research, drawing upon the information obtained from the Meteorological Organization, $137 \mathrm{cli}-$ matic variables affecting the distribution of the predominant rangeland species of Iran, were selected as climatic databases. The period of the statistical year is from 1981 to 2018 (Table 1). Since the data used in meteorological stations is point (Fig. 2) and generally, the results of climate analysis can be generalized to large areas when they are converted from point data to area data by using interpolation methods [5]. Therefore, considering to the density and variability of the selected variables and by using of the most variable parameter, which is rainfall, the Variogram was analyzed to determine the appropriate distance size of the network dimensions, so that based on the result of Variogram analysis, a suitable interval, was specified to determine the size of this network. Therefore, the size of $35 \times 35 \mathrm{~km}$ was chosen for Iran, and considering these dimensions, a Matrix with 137 columns (variables) and 1267 rows (location) for Iran was obtained and the values of climatic variables were estimated by kriging method in each of the locations. Then, the KMO method was used to investigate the performance of factor analysis [5]. The ultimate goal of factor analysis is two matrices of loading Factor and factor score, which all of the interpretations are performed on these two matrices. The loading Factor matrix explains the correlation between the factors resulting from the factor analysis and the main variables used to make the factors, another matrix is the Factor score matrix, which shows the spatial pattern of factors in the study area (Iran). And to draw the map of factors and are used as primary data for cluster analysis. In this research, factor analysis is performed by Principal component analysis and Varimax rotation on the primary data matrix, and finally, the number of variables reduced. The factors that, variance or their specific value, is less than one are no better than one principal variable. Because the variance of each main variable is one [5]. Therefore, in this study, the factors which had a specific value of more than one were selected. At the same time, Fig. 2 in this study shows the number of suitable factors for this study. Cluster analysis was an important step in determining the number of homogeneous clusters in this study.
Table 2 Viewpoint on KMO coefficient [5]

\begin{tabular}{ll}
\hline Amount of K.M.O & Data fit for factor analysis \\
\hline Greater than or equal to 90 & perfect \\
$80-90 \%$ & Very good \\
$70-80 \%$ & Good \\
$60-70 \%$ & Normal \\
$50-60 \%$ & Weak \\
Less than $50 \%$ & Unacceptable \\
\hline
\end{tabular}

This was done by the wards method. First, the whole of Iran was divided into two climatic zones, and the climatic factors separating Iran into two zones were identified. Then 2 areas were divided into 3 areas and this was done until the final stage and at each stage, the factors separating the climatic zones were identified, the meaning of the final stage is the stage at which the number of suitable and final zones is obtained. And when we reached from the climatic zone of 25 to zone of 26 , all suitable climate zones of Iran were obtained by cluster analysis. So that, while we proceeded from the zoning phase of 26 to 27 and up, it had no effect on climate factors, and no factor was identified as a separating factor of climatic zones. Eventually, based on the multivariate statistical methods, 26 bio-climatic zones for Iran was obtained (Fig. 13). In the next step, the vegetation map of Iran with a scale of 1:250,000 (prepared by the Forests and Rangelands Organization of Iran) was networked by the kriging method and matched with the map of Iran's cellular network (which in this study, the whole of Iran, including 1267 cells, with grid dimensions of $35 \mathrm{~km}$ * $35 \mathrm{~km}$ network). And vegetation and dominant species were identified in each of the 1267 locations (network cells) and in each bio-climatic zone.

\section{Results}

To examine the adequacy of this method is found to be the first step in the implementation of factor analysis is. Which is possible by calculating the K.M.O (Kaiser-Meyer-Olkin) coefficient. The value of the K.M.O coefficient in this study obtained 0.8. That Kaiser considers that this K.M.O coefficient for factor analysis implement is a suitable and very good value (Table 2). Therefore, the coefficient of 0.806 obtained in this study shows that the usage of the factor analysis method is suitable for this work. By applying the factor analysis on the primary data matrix, 9 factors with eigenvalue, greater than one were obtained (Fig. 3). Therefore, it can be concluded that the bio- climatic zones of Iran are the result of the interaction of these nine factors, which totally accounted for $92.35 \%$ of the variance of the 
Fig. 3 The scree plot showing the number of suitable factors

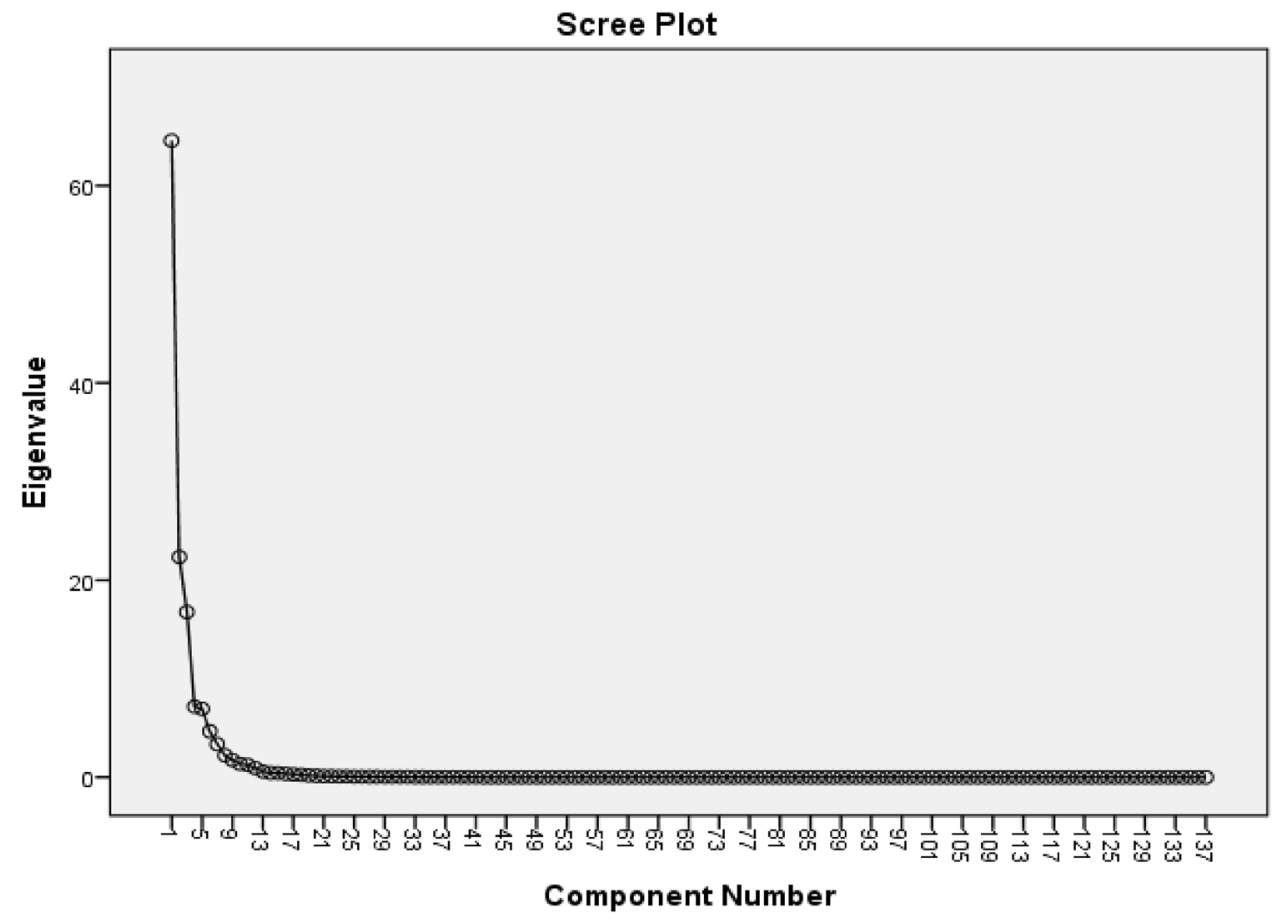

Table 3 Eigen values, percentage of variance and cumulative variance of each factor

\begin{tabular}{llll}
\hline Factors & Eigenvalue & $\begin{array}{l}\text { Variance percent- } \\
\text { age }\end{array}$ & $\begin{array}{l}\text { Cumula- } \\
\text { tive vari- } \\
\text { ance }\end{array}$ \\
\hline 1 & $13 / 46$ & $71 / 29$ & $71 / 29$ \\
2 & $80 / 19$ & $32 / 22$ & $04 / 52$ \\
3 & $16 / 8$ & $58 / 9$ & $62 / 61$ \\
4 & $72 / 5$ & $52 / 7$ & $15 / 69$ \\
5 & $3 / 13$ & $6 / 22$ & $95 / 75$ \\
6 & $3 / 95$ & $6 / 80$ & $17 / 82$ \\
7 & $27 / 2$ & $25 / 4$ & $43 / 86$ \\
8 & 2 & $69 / 3$ & $12 / 90$ \\
9 & $79 / 1$ & $22 / 2$ & $35 / 92$ \\
\hline
\end{tabular}

primary data. The eigenvalues and percentage of the variance of each factor are shown in Table 3. Another matrix that results from factor analysis and varimax rotation is the factor load matrix. This matrix is the correlation between variables and factors, first, they were sorted according to their absolute value, and then values greater than $0.7 \pm \%$ were selected and the rest were deleted (Table 4).

The reason for choosing values greater than $\pm 0.7 \%$ is that in some ways these numbers show the correlation between parameter and factor. And due to a failure in the values of the numbers after \pm 0.7 , which suddenly reaches the value of 0.3 and less, the value of \pm 0.7 was selected as the boundary. As regards, which factor score values have been standardized, they have a mean of zero and a variance of 1 , according to the above explanations, the following factors were extracted and named.

Within this matrix, the numbers of each column are correlated between a given factor and the main variables. The Table 4 shows the rotation of loading matrix in this research.

\subsection{The rotation of loading matrix}

In this matrix, the numbers of each column are correlated between a particular factor and the main variables. The Table 4 shows the rotation of loading matrix in this study.

\subsection{Naming of the factors}

In this matrix, the numbers of each column are correlated between a particular factor and the main variables, and to naming of the factors, the variables that had the highest correlation with the relevant factor were used in naming that factor, these factors are:

\subsection{Temperature}

This factor explains $29.71 \%$ of the total variance data, according to Table 4, thirty-three variables had a positive correlation of more than $0.7 \%$ with this factor, whereas all variables related to temperature (maximum monthly temperature, minimum monthly temperature, daily temperature of 12 months and etc.), as well as variables of maximum annual temperature, minimum annual temperature 
Table 4 Rotated factor loading matrix greater than \pm 0.7

\begin{tabular}{|c|c|c|c|c|c|c|c|c|c|}
\hline \multirow[t]{2}{*}{ Variables } & \multicolumn{9}{|l|}{ Factors } \\
\hline & Temperature & $\begin{array}{l}\text { Relative } \\
\text { humidity }\end{array}$ & $\begin{array}{l}\text { Cold season } \\
\text { rainfall }\end{array}$ & $\begin{array}{l}\text { Warm sea- } \\
\text { son rainfall }\end{array}$ & Wind speed & $\begin{array}{l}\text { Semi- } \\
\text { cloudy days }\end{array}$ & Dust & Thunder & Snow \\
\hline $\operatorname{AminTjan}_{*}$ & .9 & & & & & & & & \\
\hline AminTfeb & .9 & & & & & & & & \\
\hline aminTmar & .9 & & & & & & & & \\
\hline aminToct & .9 & & & & & & & & \\
\hline aminTnov & .9 & & & & & & & & \\
\hline aminTdec & .9 & & & & & & & & \\
\hline aminTannual & .9 & & & & & & & & \\
\hline Dwfreezjan $*$ & -.9 & & & & & & & & \\
\hline Dwfreezfeb & -.9 & & & & & & & & \\
\hline Dwfreezdec & -.9 & & & & & & & & \\
\hline Dwfreezannual & -.9 & & & & & & & & \\
\hline amaxTmar & .8 & & & & & & & & \\
\hline amaxTapr & .8 & & & & & & & & \\
\hline amaxTmay & .8 & & & & & & & & \\
\hline amaxTjuan & .8 & & & & & & & & \\
\hline amaxTjuly & .7 & & & & & & & & \\
\hline amaxTaug & .7 & & & & & & & & \\
\hline amaxTseb & .8 & & & & & & & & \\
\hline amaxToct & .9 & & & & & & & & \\
\hline amaxTannual & .8 & & & & & & & & \\
\hline ADTjan $^{*}$ & .9 & & & & & & & & \\
\hline ADTfeb & .9 & & & & & & & & \\
\hline ADTmar & .9 & & & & & & & & \\
\hline ADTapr & .9 & & & & & & & & \\
\hline ADTmay & .9 & & & & & & & & \\
\hline ADTjuan & .9 & & & & & & & & \\
\hline ADTjuly & .8 & & & & & & & & \\
\hline ADTaug & .9 & & & & & & & & \\
\hline ADTseb & .9 & & & & & & & & \\
\hline ADToct & .9 & & & & & & & & \\
\hline ADTnov & .9 & & & & & & & & \\
\hline ADTdec & .9 & & & & & & & & \\
\hline ADTannual & .9 & & & & & & & & \\
\hline ARHmar & & .8 & & & & & & & \\
\hline ARHapr & & .8 & & & & & & & \\
\hline ARHmay & & .8 & & & & & & & \\
\hline ARHjuan & & .8 & & & & & & & \\
\hline ARHseb & & .9 & & & & & & & \\
\hline ARHoct & & .9 & & & & & & & \\
\hline ARHannual $_{*}$ & & .9 & & & & & & & \\
\hline AmaxRHmar & & .9 & & & & & & & \\
\hline AmaxRHapr & & .9 & & & & & & & \\
\hline AmaxRHmay & & .7 & & & & & & & \\
\hline AmaxRHjuan & & .7 & & & & & & & \\
\hline AmaxRHseb & & .8 & & & & & & & \\
\hline AmaxRHoct & & .9 & & & & & & & \\
\hline AmaxRHannual $_{*}$ & & .9 & & & & & & & \\
\hline
\end{tabular}

\section{SN Applied Sciences}


Table 4 (continued)

\begin{tabular}{llr}
\hline Variables & Factors \\
\cline { 2 - 3 } & Temperature & Re \\
& \\
& & hu \\
\hline AminRHmar & .8 \\
AminRHapr & .8 \\
AminRHmay & .9 \\
AminRHjuan & .9 \\
AminRHse & .9 \\
AminRHoct & .9 \\
AminRHannual & & .9
\end{tabular}

rainjul

rainaug

rainseb

rainoct

rainnov

raindec

rainannual

Dwthuannual

DWDUSTmay*

DWDUSTjuan

DWDUSTjuly

DWDUSTaug

DWDUSTseb

DWDUSTannual

wapr

wmay

wjuan

wjuly

Waug*

wsep

woct

wnov

wdec

wannual

pclannual

DWR10winter*

DWR10summer

DWR10autumn

DWR5winter *

DWR5summer

DWR5autumn

DWSNOWspring

DWSNOautumn

AminTjan $^{*}=$ average minimum temperature, Dwfreezjan* ${ }^{*}$ day with freezing, $A m a x T^{*}=$ average maximum temperature, $A D T^{*}=$ average mean daily temperature, $\mathrm{ARHjan}^{*}=$ average relative humidity percent, $\mathrm{AMax} \mathrm{RHannual}^{*}=$ average maximum relative humidity percent, Amin RHP annual ${ }^{*}$ average minimum relative humidity percent, rainjan annual ${ }^{*}=$, monthly total rainfall, dwrjul ${ }^{*}=$ day with rainfall in July, DWR10winter* ${ }^{*}$ days with rainfall more than $10 \mathrm{~mm}$ in winter, DWR5winter* =days with rainfall more than $5 \mathrm{~mm}$ in winter Dwthumar* $^{*}$ days with thunder storm, DWDUSTmay* $=$ days with dust in May, Waug* =average wind speed in august, pcljan* $=$ partly cloudy days in Jan, cljan* cloudy days in Jan, DWS days with snow 


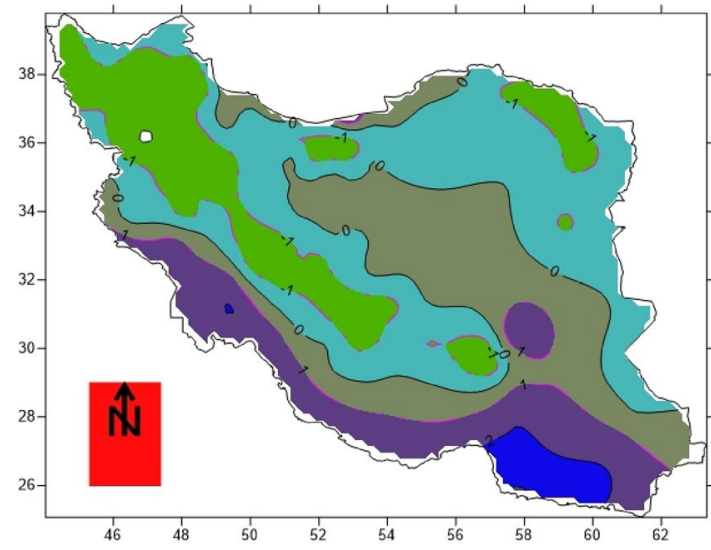

Fig. 4 Spatial distribution of temperature factor in Iran

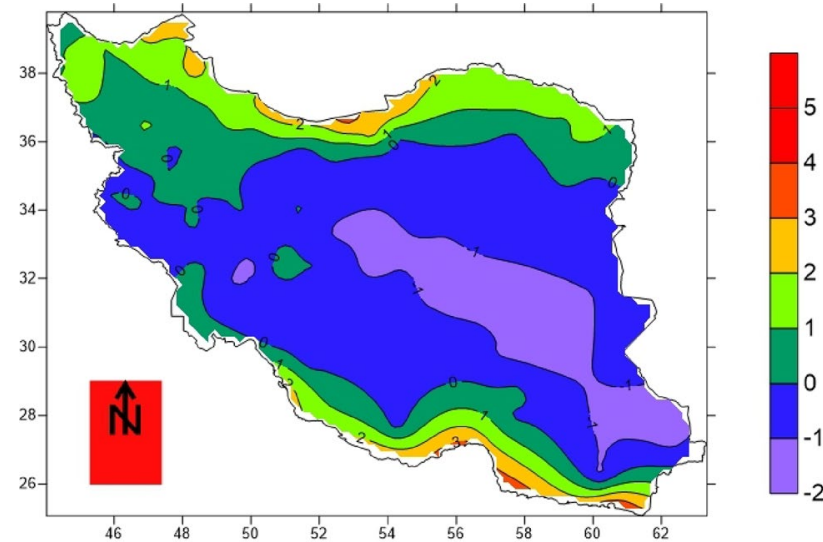

Fig. 5 The spatial distribution of relative humidity factor in Iran

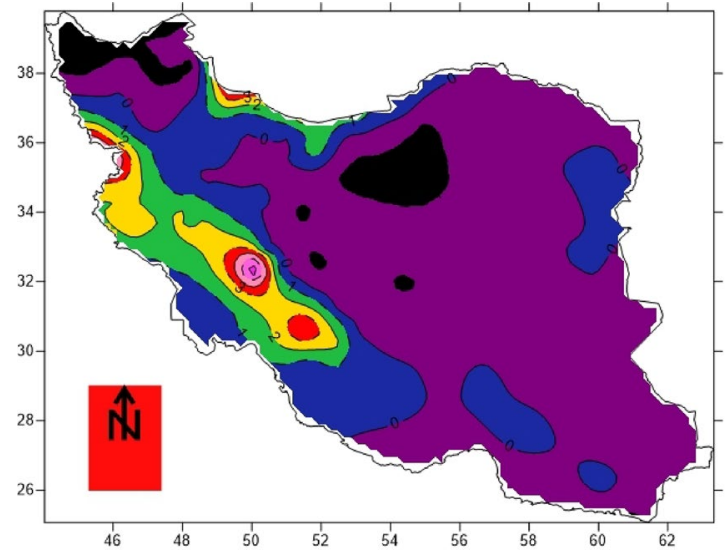

Fig. 6 The spatial distribution of cool season rainfall factor in Iran

and annual temperature are in this subgroup. For this reason, this factor is named temperature. Figure 4 shows the spatial distribution of this factor in Iran. Almost from the

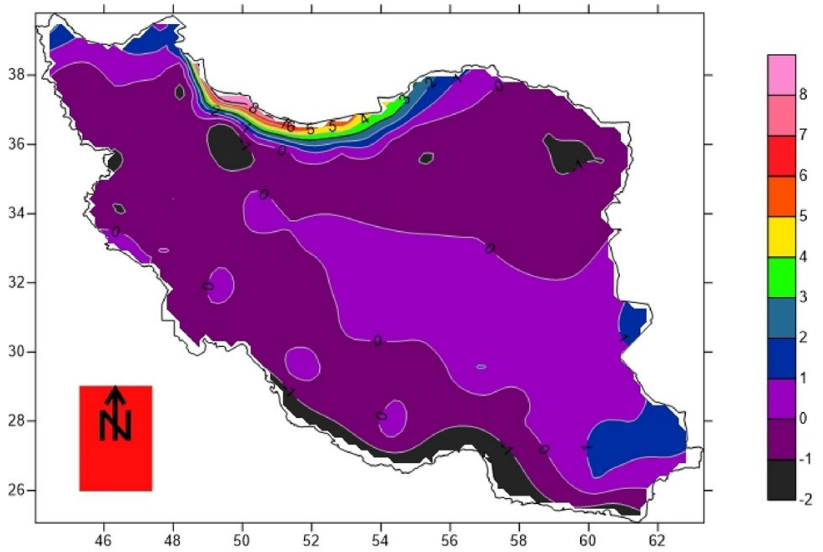

Fig. 7 The spatial distribution of warm season rainfall factor in Iran

center of Iran to the east and southeast of Iran, the amount of this factor increases and from the central regions of Iran to the west and northwest of Iran due to high altitudes, the amount of this factor decreases.

\subsection{Relative humidity}

This factor explains $22.32 \%$ of the variance of the primary variables. According to Table 4, twenty variables have more than $0.7 \%$ correlation with this factor. And since that all of the variables related to relative humidity exist in this subgroup, this factor is named the relative humidity. Figure 5 shows the spatial distribution of this factor across the whole of Iran. As can be seen, the highest percentage of relative humidity, is related to the northern and southern regions of Iran, which are close to water sources.

\subsection{Cool season rainfall}

This factor explains $9.58 \%$ of the total variance of the primary variables, variables such as rainfall in winter and autumn seasons and rainfall in January, February, March, November, December, annual rainfall and etc., belong to this group, so this factor is named the Cool season rainfall, also the spatial distribution map of this factor is shown throughout Iran (Fig. 6). As can be seen, in the western and northwestern highlands of Iran, where the Alborz Mountains are located, this factor has high and positive values.

\subsection{Warm season rainfall}

This factor lonely explains $7.52 \%$ of the total variance of the primary variables, the reason for naming this factor including variables such as rainfall in months of July, August and September, days with rainfall in summer and days with more than $5 \mathrm{~mm}$ rainfall in summer, that have a

\section{SN Applied Sciences}




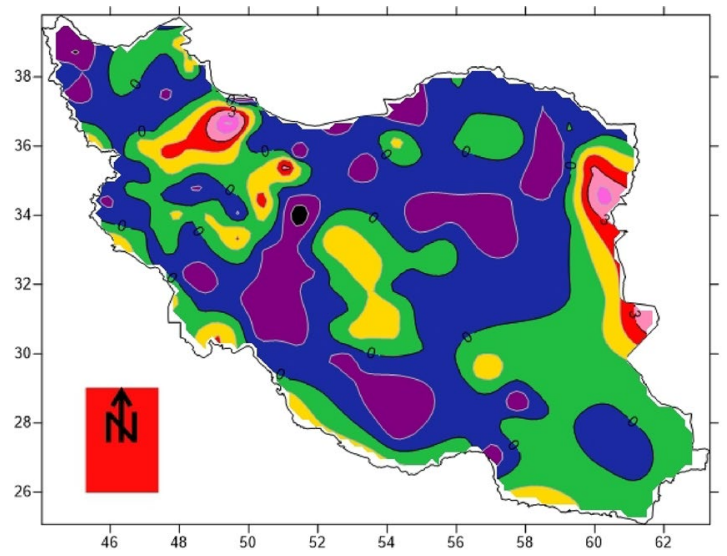

Fig. 8 The spatial distribution of Wind speed factor in Iran

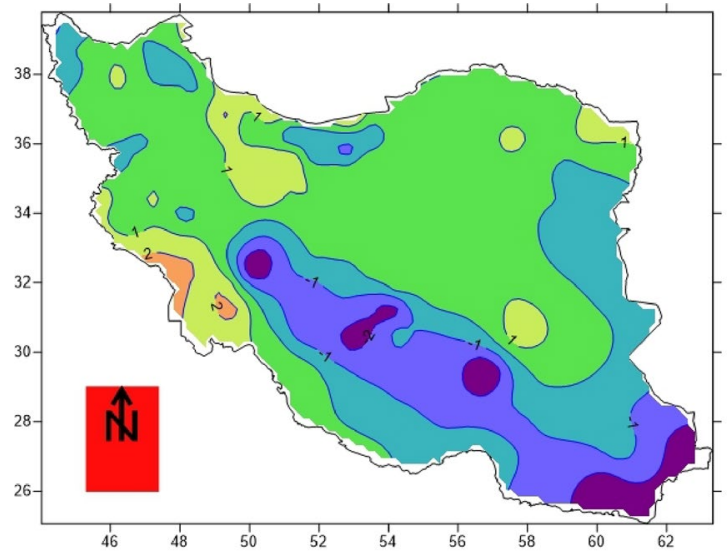

Fig. 9 The spatial distribution of semi-cloudy day's factor in Iran

strong correlation with more than $0.7 \%$ in subgroup. Figure 7 shows the spatial distribution map of this factor in Iran which in northern Iran and the Caspian Sea region, the amount of this factor is very high. Meanwhile in the central, eastern and southeastern regions of Iran, the amount of this factor is higher than the rainfall factor of cold seasons, which are located in these regions.

\subsection{Wind speed}

This factor was strongly correlated with all variables related to average of wind speed (all wind speed variables) and demonstrated the role of this factor in the effectiveness of separation of bioclimatic zones, particularly in east and southeastern of Iran. In this study all of relevant variables related to this factor, explained $6.22 \%$ of primary variables from total variance. And according to Fig. 8 the spatial distribution map of this factor is clearly shown throughout

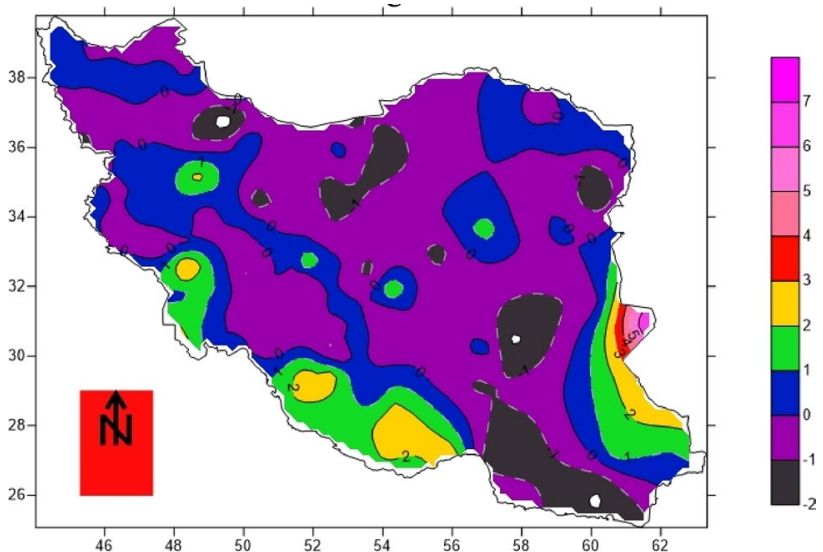

Fig. 10 The spatial distribution of dust factor in Iran

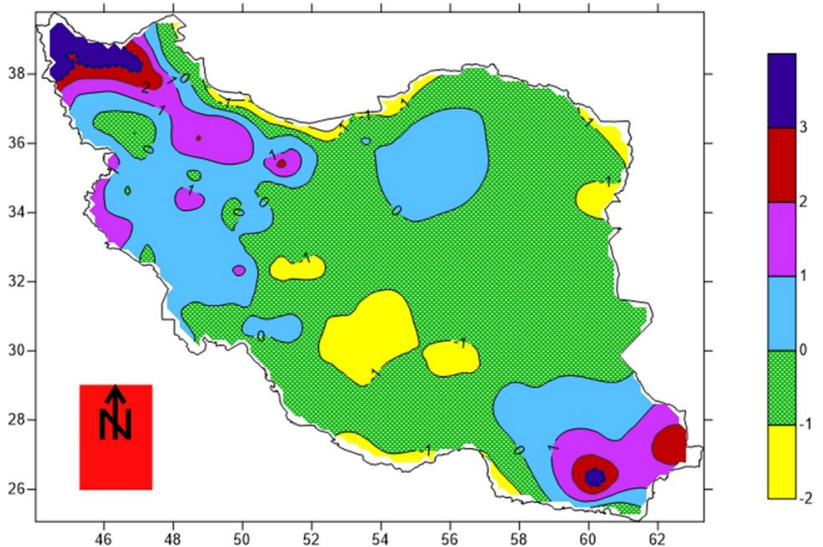

Fig. 11 The spatial distribution of thunder storm factor in Iran

Iran. As can be seen, the highest amount of this factor is in east and southeastern of Iran, especially the north area of Sistan and baluchestan province.

\subsection{Semi-cloudy days}

This factor was only strongly correlated with the annual semi-cloudy variable. For this reason this factor named semi-cloudy day's factor. According to Fig. 9 the distribution map of this factor throughout Iran is clearly shown.

\subsection{Dust}

This factor explains $4.25 \%$ of the total variance of the primary variables, the variables of the days with dust in April-May-June-July-August-September months and the days with annual dust were included in this 


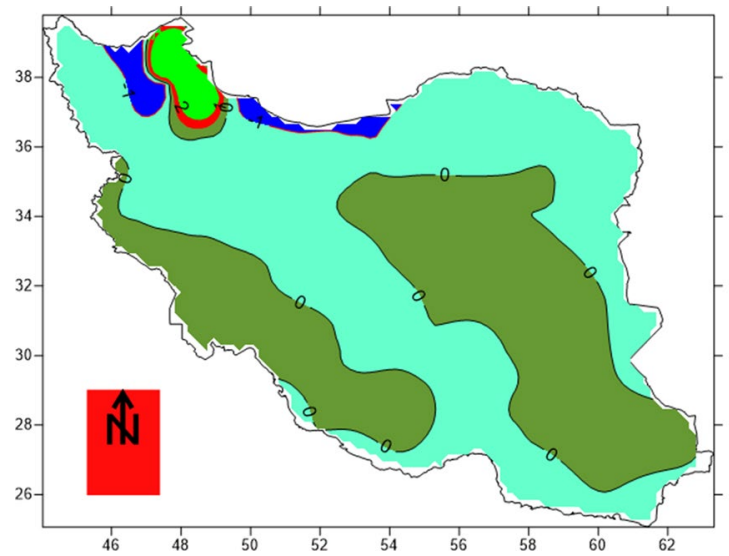

Fig. 12 The spatial distribution of snow factor in Iran

subgroup and had a strong correlation of more than $0.7 \%$ with this factor, so this factor named dust. Figure 10 shows the spatial distribution map of this factor in Iran and according to this map, the highest amount of the dust factor is in the Sistan and baluchestan province in southeast of Iran, areas in southern and southwestern Iran also have high amounts of this factor.

\subsection{Thunder storm}

This factor lonely explains $2.22 \%$ of the total variance from primary variables, and variables of days with thunder storm in June month and days with annual thunder showed a strong correlation and more than $0.7 \%$ with this factor and was the reason for naming this factor. Figure 11 shows the spatial distribution map of thunder storm throughout Iran.

\subsection{Snow}

This factor was named as the final factor and effective in this study which explains $1.29 \%$ of total variance from primary variables. Variable such as days with snow in season of winter, spring and autumn were correlated above $0.7 \%$ with this factor and according to Fig. 12 the spatial distribution map of this factor has been shown in Iran (Fig. 13).

\subsection{Cluster analysis}

\subsubsection{Wards cluster analysis and determination the number of groups (homogeneous clusters)}

Clustering by the Minimum variance method or total square errors (known as the Wards method, presented by [30] is very attractive intrinsically. Because it is based on a simple principle that at each stage of clustering, the variance within the clusters is minimized relative to the variance between the clusters, and at each stage, the two clusters are combined which to have the least (minimal) increase in variance. This strategy is repeated until it

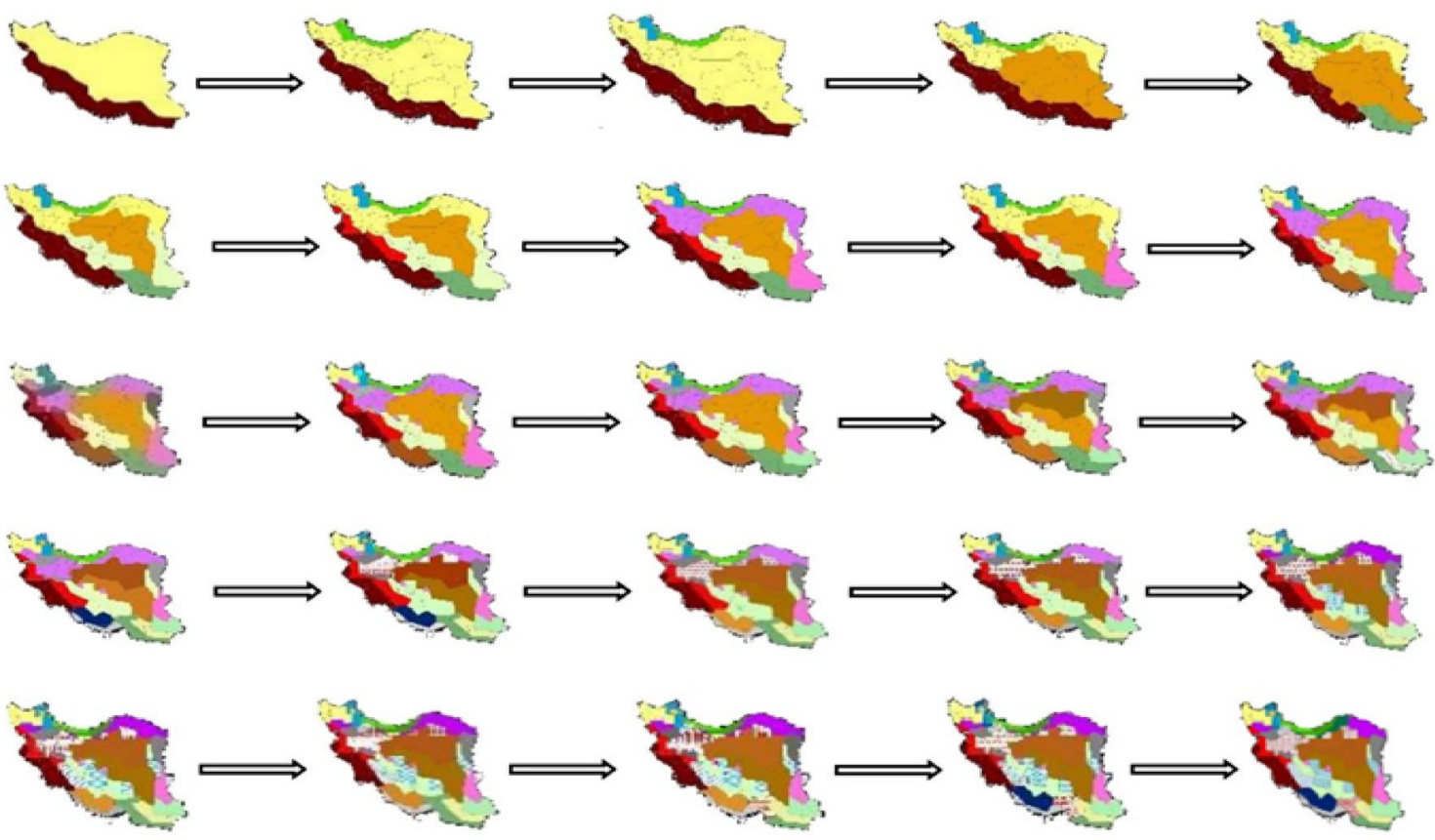

Fig. 13 Separation of climatic zones (from zone 2 to the final zone, 26) based on Wards' clustering in Iran 


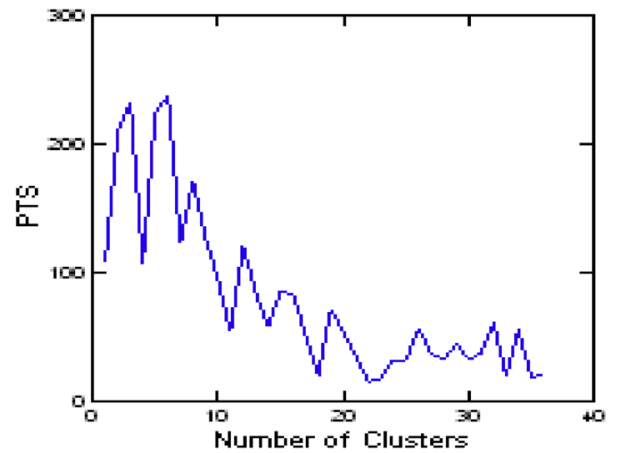

Fig. 14 The relationship between the number of groups and Pseudo T2, obtained by systat V.13 software

eventually leads to successive groups and the final result is optimized. This method was also used in this study. Also, data in the Table 5 shows how to determine the most appropriate number of clusters by using Systat V.13 statistical software. The data in this table show the relationship between Pseudo T2 and Pseudo F and the number of suitable bio-climatic zones. The number of suitable bio-climatic zones is where the Pseudo T2 value associated with that zone has a steep decrease compared to the next zone. (italic row) That in a row of 26 than to 27 , there is a steep and sudden decrease in this data. The value of Pseudo T2 in this row (row of 26) is 120.89 and the data of its next row, i.e. row 27, (bold row) is equal to 37.84 . As can be seen, there is no sudden change in this value in any row. Therefore, the most appropriate number of groups based on Pseudo T2 is 26 groups. Also, Fig. 14 shows the appropriate number of groups on the chart. Considering this figure, it can be seen that between 20 and 30 groups are suitable for Iran's climatic zones.

\subsubsection{Bioclimatic classification of Iran}

Bioclimatic classification of Iran using the Pabout traditional method [19].

As per the Pabout method, Iran's bio climates map includes 3 large vegetation Caspian zone, Gulf-Omani zone and Iran and Turani zone (Fig. 15). Caspian climatic zone is in the north of Iran and located in the form of a strip from west to east along the Caspian Sea. The zone of Gulf-Omani is located in the south of Iran and closed to the Persian Gulf and Oman Sea. And approximately, the $85 \%$ remaining of Iran's territory, especially the central, eastern, and western regions of Iran, is considered to be the climate of Iran and Turani. Of course, Henry Pabout divided this wide region (Iran and Turani) into 5 subzones (semi-desert, steppe, semi-steppe, arid forests, and high mountains) based on the amount of rainfall. Also, the Caspian zone is divided according to the altitude to (vegetation area above the Caspian basin from $800 \mathrm{~m}$ and above and the lower vegetation area of the Caspian basin up to an altitude of $800 \mathrm{~m}$ ). In general, according to the Pabout method and Fig. 15, Iran has divided into 8 climatic zones (semi-desert, steppe, semi-steppe, dry forests, high

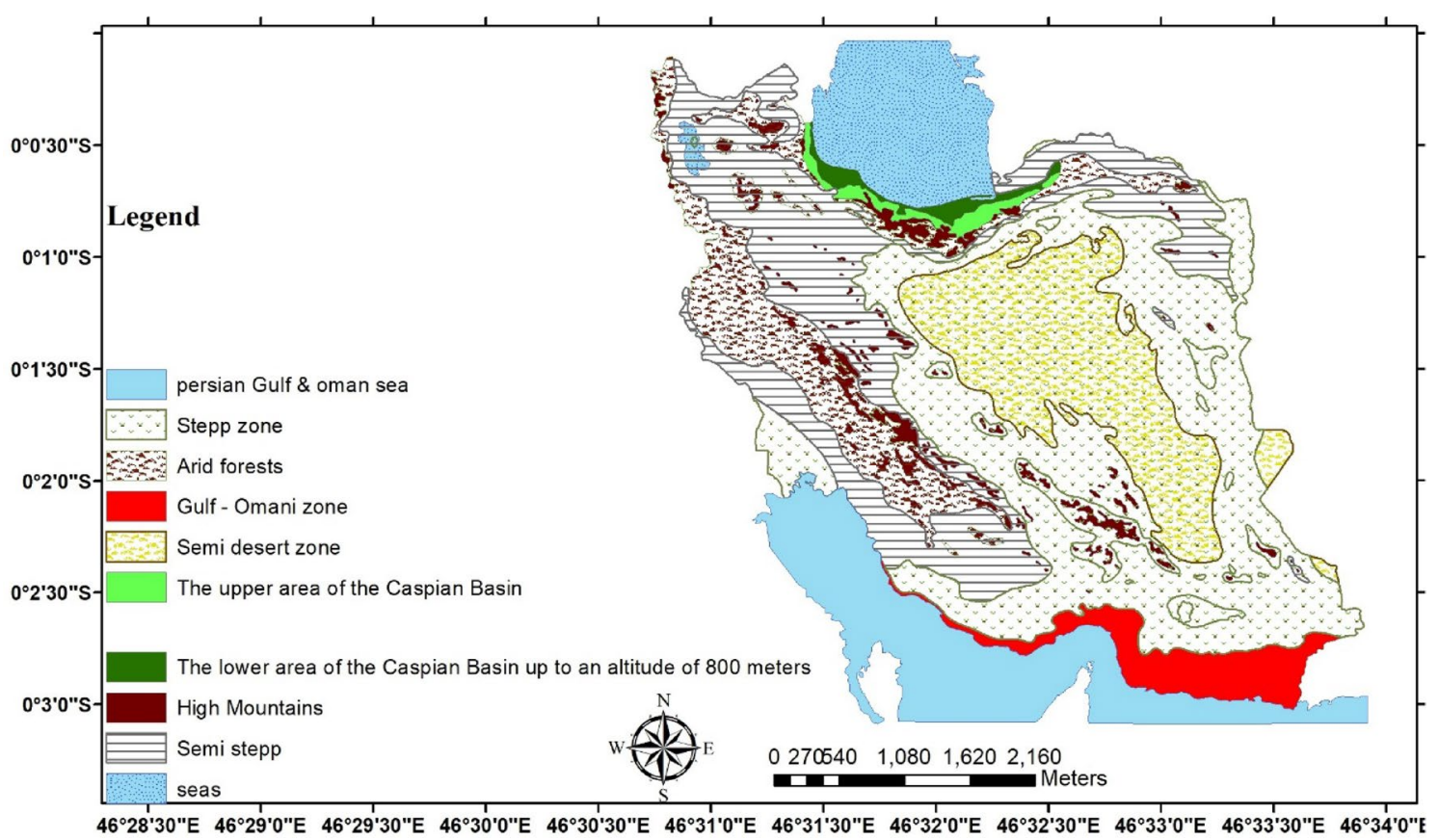

Fig. 15 Bioclimatic zonation of Iran by Pabout method 


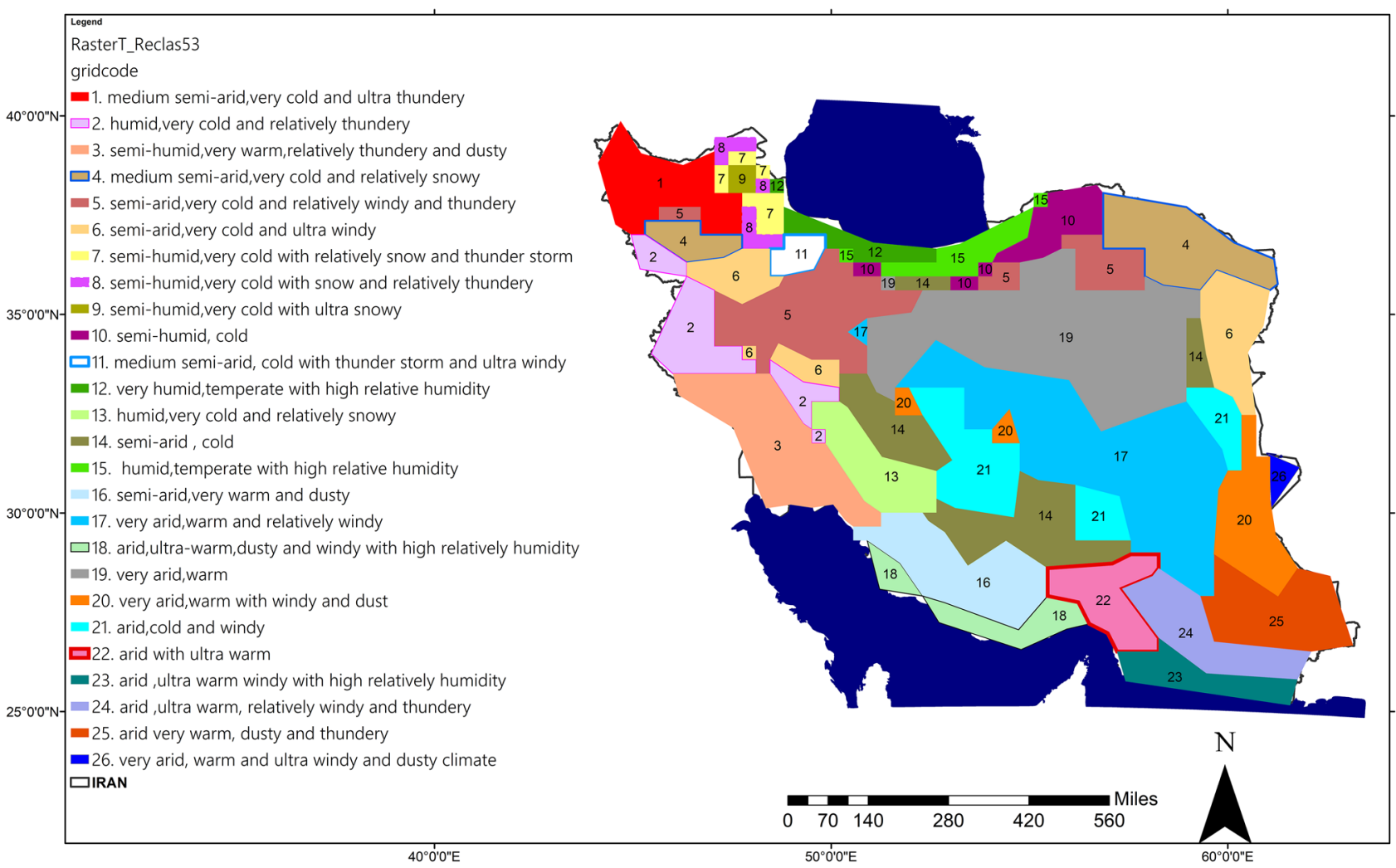

Fig. 16 The bio-climatic classification of Iran by multivariate statistical methods

mountains, Gulf-Omani, bioclimatic zone above the Caspian Basin from $800 \mathrm{~m}$ and above and the lower bioclimatic zone of the Caspian Sea up to an altitude of $800 \mathrm{~m}$ ).

\subsubsection{Bioclimatic classification of Iran by multivariate statistical methods}

Given the results of multivariate statistical methods, Iran is divided into 26 bio-climatic zones (Fig. 16) and they are as follow:

\subsubsection{Bio-climatic zone (1): medium semi-arid, very cold and ultra-storm}

This zone with an area of $12,921,233$ ha is located in northwestern Iran (Fig. 16). The average height of this area is $1685 / 93$ me, based on the data in the table of factor scores (6) the score of temperature factor in this zone is negative and very high $(-1 / 23)$. Also, the score of cold season rainfall is negative and the score of warm-season rainfall is positive. Among other factors in this zone, the thunder factor score is significant and very high (+2.99) and considering that the average annual rainfall in this area is $289 \mathrm{~mm}$ Also, due to the higher weight factors of temperature, cold and warm seasons rainfall and thunderstorms, this zone was named as the climatic zone of "medium semi-arid, very cold and ultra-thundery". The most important and dominant vegetation species in this area are: Astragalus angustiflorous, Artemisia fragrans, Acantholimon bracteatum, Agropyron imbricatum.

\subsubsection{Bio-climatic zone (2) "Humid, very cold, approximately thundery"}

This bioclimatic zone is located in the western and northwestern border areas of Iran (Fig. 16). The area of this climatic zone is $5,977,322 \mathrm{ha}$, the above sea level elevation of this climatic zone is $1637.77 \mathrm{~m}$. According to the data in the table of factor scores (6) in this bioclimatic zone, the temperature factor has a negative and approximately high score, which indicates the severe cold prevailing in this climatic zone. The factor score of cold season rainfall is positive and very high (+2.42) also, among other factors, the score of thunder factor is almost high and significant. Therefore and due to the fact that the average annual rainfall in this area is $568 \mathrm{~mm}$, this climatic zone was named "Humid, very cold and approximately thundery". The predominant and significant vegetation types in this climatic 
Table 5 The relationship between Pseudo T2 and Pseudo F, values with the number of groups

\begin{tabular}{lcc}
\hline Area number & Pseudo F & Pseudo T2 \\
\hline 29 & 214.808 & 44.751 \\
28 & 216.979 & 32.034 \\
$\mathbf{2 7}$ & $\mathbf{2 2 0 . 0 5 7}$ & $\mathbf{3 7 . 8 4 7}$ \\
26 & 263.135 & 120.893 \\
25 & 225.464 & 31.995 \\
24 & 227.618 & 32.275 \\
23 & 222.390 & 17.441 \\
22 & 217.146 & 15.424 \\
21 & 221.325 & 34.738 \\
20 & 226.708 & 54.444 \\
19 & 235.427 & 71.102 \\
18 & 233.635 & 19.888 \\
17 & 239.406 & 51.187 \\
16 & 247.033 & 82.514 \\
15 & 250.963 & 85.563 \\
14 & 253.824 & 58.655 \\
13 & 256.827 & 83.972 \\
12 & 224.170 & 56.754 \\
11 & 209.785 & 53.873 \\
10 & 210.059 & 94.845 \\
9 & 207.595 & 125.642 \\
8 & 218.671 & 170.769 \\
7 & 203.221 & 123.346 \\
6 & 201.720 & 237.692 \\
5 & 215.430 & 224.315 \\
4 & 222.024 & 107.584 \\
3 & 103.522 & 232.421 \\
2 & 109.272 & \\
1 & 0.00 & \\
\hline
\end{tabular}

zone are found in the form of Pillow and hemisphere, these vegetation types distributed in climatic conditions such as long periods of cold and low temperatures. From the most important and dominant vegetation species of this climatic zone can be mentioned to the following species: Ferula phialacarpa, Bromus tectorum, Astragalus caryolobous, Prangus crossoptera.

\subsubsection{Bio-climatic zone (3) "semi humid, very warm and relatively dusty"}

This bioclimatic zone with an area of 7.306637 ha located near the western border of Iran and includes parts of 4 provinces of Ilam, Khuzestan, Lorestan, Kohgiluyeh, and BoyerAhmad (Fig. 16).and the above sea level elevationof this area is $457.47 \mathrm{~m}$. According to the factor scores Table 6, it is noticed that in this area, the factor score of temperature is positive and very high $(+1.34)$, and also the factor score of the semi-cloudy days is almost high and positive (+0.52), the factor score Rainfall is positive and high in the cold season (+1.37), but the factor of rainfall in the warm season is negative (-0.32). On the other hand, considering that the average annual rainfall in this climate zone is $338.43 \mathrm{~mm}$, and according to the scores of factors which obtained in this zone that were mentioned and also especially the relatively high score obtained by the dust factor in this zone (0.545) this bioclimatic zone was named: semi-humid, very warm and relatively dusty zone. And from the most important and dominant species in this area can be mentioned to Salsola baryosma, Helianthemum lipii, Artemisia Sieberi, Cornulaca leucacantha species.

\subsubsection{Bio-climatic zone (4) medium semi-arid, very cold and relatively snowy}

This area covers an area of 788,276 ha, including areas in the northeast, north, and northwest of Iran (Fig. 16). The above sea level elevation of this climatic zone is $1403.51 \mathrm{~m}$. The data in Table 6 show that the temperature factor score in this zone is negative and very high $(-1.01)$. And the rainfall factor scores of the warm and cold seasons are negative, on the other hand, the factor scores of relative humidity and the semi-cloudy days in this area are very high and positive, and also the factor score of snow is positive. With these interpretations, and since the annual precipitation in this bio-climatic zone is $274 \mathrm{~mm}$, this zone was named as "medium semi-arid, very cold and relatively snowy ". The most important dominant vegetation cover in this climatic zone is the following vegetation species: Artemisia Aucheri, Acantholimon pterostegium, Astragalus esferayenicus, Acantholimon acmostegium.

\subsubsection{Bio-climatic zone (5) semi-arid, very cold, relatively windy and relatively stormy}

This climatic zone involve a large part of the northwestern regions of Iran, approximately all parts of HamadanMarkazi-Qazvin-Qom, Tehran, Semnan provinces, and northwestern parts of Central Khorasan province and a small part in the southwest of North Khorasan province with an area of $11,273,272$ ha (Fig. 16). The above sea level elevationof this climatic zone is $1570 \mathrm{~m}$. The data in Table 6 show that the factor score of temperature is high and negative $(-0.78)$ which indicates a high cold in this area. Also according to this table, the relative humidity factor is positive, the cold season rainfall factor is positive but the amount of rainfall in cold seasons is low. The score of warm-season rainfall is approximately high and negative, this means that in this bioclimatic zone, rainfall often occurs in the cold seasons of the year. The factor score of 
semi-cloudy days is also very high, which indicates that cloudy and semi-cloudy days are high in this area. The important point in this climatic zone is the score of wind speed and thunderstorm factors, especially the factor score of wind speed which is more positive and higher than the four previous zones, the wind speed factor has a great appearance in this zone. Also, when the spatial distribution map of the Thunder factor (Fig. 11) is examined, it is clear that except for the northwestern and southeastern regions of Iran in this area (bio climate zone 5) it has an almost higher distribution than other regions of Iran. This indicates that wind speed and thunder factors have a high appearance in this area and have a decisive role in the formation of this bio-climate zone, and especially on the vegetation cover of the dominant species in this climatic zone. With these interpretations, this climate zone was named "semi-arid, very cold, relatively windy and relatively thundery". And the most important species in this zone are Scariola orientalis, Cousinia multiloba, Astragalus squarrosus, and Centaurea virgate species.

\subsubsection{Bio-climatic zone (6) semi-arid, very cold and ultra-windy}

This bio- climatic zone with an above sea level elevation of 1533/34 $\mathrm{m}$ and an area of 7,633,005 ha is located in the eastern regions of Iran (closed to the border areas in the eastern part of Iran, a large part of southeastern and eastern central Khorasan province and a small part in northeastern South Khorasan province) (Fig. 16). The results of the factor scores table (Table 6) show that in this climatic zone, the scores of temperature factor, warm-season rainfall, semi-cloudy days, snow, dust, and thunderstorms are negative and other factors have positive scores. Since the score of temperature factor is approximately high and negative $(-0.99)$ and the factor score of cold season rainfall almost is high and positive $(+0.46)$ and also the wind speed factor has of a very high and positive score in this zone and this three (3) factors have a high appearance in this climatic zone, and considering that the average annual precipitation in this climatic zone is $259 \mathrm{~mm}$, this climatic zone was named "very cold, semi-dry and ultra-windy". The most important vegetation species predominant in this area are the following species: Launea acanthodes, Scariola orientalis, Ar. sieberi, Ephedra intermedia (persica), Eringium bungei, Cousinia trachyphyllaria and Ziziphora clinopodioides.

\subsubsection{Bio-climatic zone (7) "semi humid, very cold, thundery and relatively snowy"}

As a whole, the total area of this climatic zone is 1,499,589 ha. And as shown in Fig. 16, this vegetation zone in the west of the Caspian Sea includes large parts of Ardabil province, parts of northern Zanjan province and small areas in northeastern, eastern and southeastern provinces of East Azerbaijan province. The above sea level elevationof this area is $5652.58 \mathrm{~m}$. The results of Discriminant analysis in relation to climatic factors and this climatic zone show that the scores of temperature, cold season rainfall, and dust factors in this area are negative and the rest of the factors have positive scores (Table 6). The score of temperature factor is negative and very high $(-1.22)$ also the factor score of relative humidity is positive and very high and this means that the relative humidity in these areas is high and the temperature is very cold. And since that the score of warm-season rainfall factor is positive and the average annual rainfall in this area is $396 \mathrm{~mm}$ (close to $400 \mathrm{~mm}$ ) and also the score of Thunderstorm and snow factor is high and relatively high respectively, this zone was named: semi-humid, very cold, thundery and relatively snowy, from the most important vegetation cover of this area, which is an indicator and adaptable with the climatic and ecological conditions of this area, can be mentioned as follows: Artemisia Sieberi, Astragalus caraganae, Onobrychis atropatana.

\subsubsection{Bio-climatic zone (8) "semi-humid, very cold, snowy and relatively thundery"}

This vegetative area with a 1270/170 m above sea level elevation and an area of 1,329,219 ha is located in the northwest of Iran and close to the climatic climate of 7. The results of discriminant analysis to obtain the mean score of climatic factors in this bio-climatic zone according to Table 6 show that in this climatic zone the factor score of temperature is approximately very high and negative (97/0-). Also, the score of the cold season rainfall factor is negative, but the factor score of the warm season rainfall is positive, and since that the average annual precipitation in this Bio-Climatic zone is $314 \mathrm{~mm}$, this climatic zone was named semi-humid, very cold. Also, since in this zone the amount of snow and Thunder factors were high and relatively high, respectively and by interfering of these 4 factors that were most apparent in this climatic zone, eventually was named:' semi-humid, very cold, snowy and relatively thundery" and the species vegetation that is most important and dominant in this zone are Artemisia Sieberi, Astragalus caraganae, Onobrychis atropatana.

\subsubsection{Bio-climatic zone (9) "semi humid, very cold and ultra-snowy"}

This bioclimatic zone is nestled over in the west of the Caspian Sea and between zones 7 and 8. The climatic zone with an area of $0.491607 \mathrm{ha}$, includes the most of areas in 
the central areas of Ardabil province. That the altitude of this bioclimatic zone is $203,150 \mathrm{~m}$ above sea level elevation, as can be seen, in this climatic zone, and according to the Table 6 the average score of the temperature factor in this zone is negative and very high valuable $(-1.20)$, which indicates that in this zone the climatic elements related to the temperature factor, their values are decreasing and very cold condition Also, the average factor score of cold seasonal rainfall in this climatic zone is negative, which shows that the score of climatic elements related to rainfall factors of cold seasons in this zone is lower and lower than the score of climatic elements related to rainfall of warm seasons in this bioclimatic zone, which in contrast, the elements associated with this factor are increasing, and as a result, the score of the warm season rainfall factor is positive and more positive than the cold season rainfall factor. Also, due to the high score of the snow factor in this zone, which has the highest relevant score among the 26 climatic zones. And since the score of the temperature factor is negative and very low and on the other hand the factor scores of the warm season rainfall and relative humidity factors were high and also the average annual rainfall in this zone is $324 \mathrm{~mm}$, this bioclimatic zone was named "semi-humid, very cold and ultra-snowy"The most important predominant vegetation types in this climatic zone are: Festuca Ovina, Artemisia aucheri, Onobrychis atropatana.

\subsubsection{Bio-climatic zone (10) "semi-humid and cold"}

This bioclimatic zone with an area of $3,352,127$ ha is located in the northeastern of Iran. And include the southern moiety of Golestan province, the northern and northwestern parts of North Khorasan province, and the northern parts of Semnan province (Fig. 16). The above sea level elevationof this climatic zone is 2998/29 m, according to the results of Discriminant analysis in this climatic zone, it is noticed that the factor score of temperature factor is negative and approximately low $(-0.26)$ Also, because that the factor score of warm-season rainfall is positive and almost high (+0.87) and on the other hand the relative humidity factor has a positive and high score $(+1.44)$ and whereas the average annual rainfall in this area is $314 \mathrm{~mm}$, this climatic zone was named "semi-humid and cold". The most important predominant vegetation types in this climatic zone are: Poa bulbosa, Medicago Minima, Astragalus memoriosus, Hordeum glaucum, Suaeda salsa.

\subsubsection{Bio-climatic zone (11) “Medium semi-arid, cold, stormy and ultra-windy"}

This climate zone has an area of $1,187,314$ ha in the southern regions of Gilan province [Rudbar, Manjil]
(Fig. 16). The sea above elevation of this climatic zone is $1519 / 91 \mathrm{~m}$. The results of Discriminant analysis, according to Table 6 show that in this climatic zone, the factor score of temperature factor is negative and almost low $(-0.3)$. Also, the relative humidity and cold season rainfall factors have a positive and upward score. The factor score related to wind speed is also positive and very high, and the factor score related to Thunder is also positive and significant the score of wind speed factor is positive and very high. Also, the thunderstorm has a significant and positive score. Therefore, this climatic zone, due to the appearance of most of the above factors, was named medium semi-arid, cold, thundery, and ultra-windy ". In the next step, the most important vegetation types of this bioclimatic zone are mentioned. This stage achieved by overlaying the vegetation maps to the climatic zones obtained by multivariate statistical methods. Dominant vegetation species such as Artemisia aucheri, Astragalus basilicus, Atraphaxis Aucheri adapted to this climatic conditions.

\subsubsection{Bio-climatic zone (12) "very humid, temperate with very high relative humidity"}

This climatic zone with an area of 2, 10,083 ha is located in the hillside of the Alborz Mountains and close to the shores of the Caspian Sea. And having average sea above elevation of $1117 / 93 \mathrm{~m}$, includes large areas of Mazandaran province beside all areas of Gilan province (Fig. 16). According to the data in Table 6, in the BioClimatic zone(12) the climatic factor scores of temperature, wind speed, dust, thunder and snow factors are negative, and this means that in this Bio-Climatic zone, approximately all climatic elements associated with these factors are declining and their value is decreasing. Also in this area, the score of relative humidity factor is high and positive (near to +2 ), and the scores of warm-season rainfall and cold season rainfall of the year is high and positive. This means that in this Bio-Climatic zone, the amount of precipitation is high and all of the climatic elements related to the precipitation factor have very high values (maximum value possible between all climatic zones) and since that this climate zone is very close to the shores of the Caspian Sea, as a result, this zone has a high percentage of relative humidity and due to the very high appearance of precipitation and relative humidity factors, this climatic zone was named "very humid, temperate with very high relative humidity". And the most important predominant vegetation species in this Bio-Climatic zone that are adapted to the climatic conditions of this zone are:Cynodon dactylon, Trifolium campestre, Medicago minima, Onobrychis hohenackeriana, lotus cornicalatus. 


\subsubsection{Bio-climatic zone (13) "humid, very cold and relatively snowy"}

This Bio-Climatic zone with an area of 4,175,277 ha and an above sea level elevation of $204.24 \mathrm{~m}$ is located in west of Iran (Fig. 16). In this zone, the average score of the temperature factor is negative and this indicates that the climatic elements associated with the temperature factor have low values, and so created a very cold climate. Also, the climatic elements related to the factors of relative humidity, thunder, and wind speed are low in this area and their values are small and insignificant. The notable subject in this zone is that the average factor score of cold season rainfall is very high and positive, and conversely, the score of warm-season rainfall factor is negative. And this indicates that in this bio climate zone, the rainfall mostly occurs in months of January, February, March (winter season), October, November, and December (autumn season). And in these seasons, the vegetation reaches its climax, and rangeland and watershed managers should be aware of this subject and have their own plans and decisions for optimal management of these resources in these seasons to achieve their goals. Also, due to the very high altitudes and the positive score of the snow factor in this area, in addition to rainfall, snowfall is also relatively high in this climatic zone. Since that, the average annual rainfall in this area is $627 \mathrm{~mm}$ (after the bioclimatic zone of 12, in north of Iran, which has the highest annual rainfall, this area is considered as one of the humid and rainy areas of Iran) and finally, due to the high score of the temperature factor and its negativity and positive scores of cold season rainfall and snow factors and their high amounts, this zone was named "humid, very cold and relatively snowy". And the most important predominant vegetation species in this Bio-Climatic zone that are adapted to the climatic conditions of this zone are: Astragalus macropelmatus, Daphnae mucronata, Astragalus managetta, Euphorbia helioscopia.

\subsubsection{Bio-climatic zone (14) "cold and semi-arid"}

This Bio-Climatic zone has an area of 10,441,346 ha and the above sea level elevation of this zone is 1992/11 m. According to Fig. 15, the most space of this zone is diffused in the central and northeastern regions of Iran. According to the Table 6, in this Bio-Climatic zone, among all of the climatic factors, only the score of cold season rainfall factor is positive and 8 other climatic factors have a negative score. The score of temperature factor is negative, meaning that in this climatic zone, all of the climatic elements associated with this factor, in terms of amount and quantity, have low values, and are decreasing. On the other hand, all climatic elements that related to the three factors of relative humidity, warm-season rainfall, and snow have low or very low values. In general, in terms of humidity in this climatic zone, only the climatic elements associated with the cold season rainfall factor are almost greater than the climatic elements associated with the warm season rainfall, relative humidity and snow factors and this means that in this zone, vegetation is more dependent on precipitation in winter and autumn seasons. Also, according to the data in the table of factor scores (Table 6), it can be noticed that in this zone, all climatic elements related to climatic factors such as wind speed, dust, semi-cloudy days and thunderstorm have low values, which Finally, the scores of these factors are negative. Finally, due to the fact that in terms of temperature, the score of the elements related to this factor and the score of this factor (temperature factor) is negative, and also in terms of moisture, only the factor score of cold season rainfall is positive and of course not very high $(+0.01)$ and considering that the average annual rainfall in this Bio-Climatic zone is $214 \mathrm{~mm}$, this zone was named: semi-arid and cold, and the most important predominant vegetation species in this area are: Salvia Officinalis, Hammada Salicornica, Salsola arbuscula, Dendrostellera lessertii.

\subsubsection{Bio-climatic zone (15) “humid, temperate with very high relative humidity"}

This Bio-Climatic zone with an area of $2,620,357$ ha is located on the northern coast of Iran [south of the Caspian Sea and north of the Alborz Mountains] (Fig. 16). And after the climatic zone of 12, compared to the amount of rainfall in warm and cold seasons, is the wettest climate zone in Iran. The data in Table 6 show that in this zone, the temperature factor has a negative score, but its value is not very high. On the other hand, the average score of the relative humidity factor in this area is positive and very high, and considering that it is located near to a large source of water (Caspian Sea), this indicates that this climatic zone has balance conditions in terms of thermal conditions. With these interpretations and according to the manifestation of the factors of "warm seasonal rainfall, cold seasonal rainfall, relative humidity and semi-cloudy days" this climatic zone was named "moderate humidity, with very high relative humidity". With these interpretations (explanation) and according to the high appearances of the factors of "warm seasonal rainfall, cold seasonal rainfall, relative humidity and semi-cloudy days" this climatic zone was named "humid, temperate with very high relative humidity". And the most important of vegetation types that are dominant in the zone are Hordeum spontaneum, Cynodon dactylon, Poa bulbosa, and Medicago sativa species. 


\subsubsection{Bio-climatic zone (16) "semi-arid, very warm and dusty"}

This Bio-Climatic zone with an area of $6,869,169$ ha and above sea level elevation of $111 / 18 \mathrm{~m}$ is located in the south and southwest of Iran (Fig. 16). According to the results of Discriminant analysis and Table 6 in this zone, the score of temperature factor is very high and thermal conditions are very warm in this Bio-Climatic zone, Also, the relative humidity factor score is positive, which means that all climatic elements associated with this factor are high and increasing. The positive score of cold season rainfall in this area indicates the better conditions of the climatic elements related to this factor, which received higher values in this zone. The significant point in this area, is the factor score of dust, which has a positive and very high score compared to the previous zones, with these interpretations, and considering that the average annual precipitation in this climatic zone is $220.47 \mathrm{~mm}$, this zone was named "semi-arid, very warm and dusty". Also, the most important predominant vegetation species in this Bio-Climatic zone are: Polygonum corrigioloides, Convolvolus spinosus, Hammada salicornica and Fagonia sp.

\subsubsection{Bio-climatic zone (17) "very arid, warm and relatively windy"}

This Bio-Climatic zone with an area of $18,839,356$ ha and an above sea level elevation of 109/20 m above sea level is located in the central regions of Iran, Fig. 16 discriminant analysis was performed to the determination of mean climatic factor scores affecting the vegetation species distribution in this climatic zone, and according to Table 6, it is observed that in this climatic zone, the average score of the climatic factor of temperature is the almost high and positive score $(+0.47)$ and this means that in this zone, the climatic elements associated with the temperature factor have almost high values and indicate the warm conditions prevailing in this zone. In this climatic zone, most of the rainfall occurs in the warm seasons of the year and the amount of rainfall in the warm seasons is higher than the rainfall which occurs in the cold seasons of the year (according to the factor scores of these two factors in Table 6). Also, all climatic elements related to the factors of relative humidity, snow, thunder, and dust in this zone, include a very low rate and little amounts. Finally and with previous explanations and also, since the temperature factor has a high appearance and positive score in this zone, and also the average climatic elements associated with wind speed in this zone are relatively high, and also, the average annual rainfall in this zone is $84 \mathrm{~mm}$. This BioClimatic zone was named " very arid, warm and relatively windy." And the most important species adaptable with these climatic conditions in this climatic zone are Hammada salicornica, Anabasis aphylla, Prosopis koelziana, Tamarix aphylla, Anabasis annua.

\subsubsection{Bio-climatic zone (18) "arid, windy and dusty, extremely warm (sultry) with high relative humidity"}

This Bio-Climatic zone with an area of 4,961,219 ha is located in the southern regions of Iran and very close to the Persian Gulf and the Oman Sea (Fig. 16). The above sea level elevation of this vegetation zone is $342 / 64 \mathrm{~m}$. According to the data in Table 6, climatic factors of temperature, relative humidity, wind speed, and dust have a positive and high factor score in this climatic zone, this means that these four factors play a decisive role in the creation and distribution of vegetation and ultimately in determining the type (pattern) of climate in this zone, and other climatic factors in this vegetation zone have a negative score, in other words, they do not have an important and decisive role in creating a Bio-Climatic zone in this area. Due to the geographical location of this area, which is located on the Margin of the Persian Gulf and the Oman Sea (large water resources) and factor scores of relative humidity and temperature factors are high and very high scores respectively, on the other hand, the Climate factors of Wind speed and dust have a positive and high score and had a higher appearance in this area. And as regards that were allocated negative scores to climatic factors of warm and cold season rainfall in this zone, and also, the average annual rainfall in this area is $181.77 \mathrm{~mm}$, this zone was named: is " Arid, windy and dusty, extremely warm (sultry) with high relative humidity." And Vegetation species adaptable with these conditions in this zone are the predominant species of Halocnemum strobilaceum, Gymnocarpus decander, Platychaete glaucescens, Anvilea gracini, Platychaete aucheri.

\subsubsection{Bio-climatic zone (19) "very arid and warm"}

According to Fig. 16, this Bio-Climatic zone with an area of $20,288,367$ ha and an above sea level elevation of 10/04/06 $\mathrm{m}$, is located in the center of Iran and includes areas of Isfahan, Qom, Tehran, Semnan, Central Khorasan, and South Khorasan provinces. Also, parts of the desert plain include this area, the results of Discriminant analysis (Table 6) in this zone showed that the factor of semi-cloudy days has a positive score, and this means that the all of climatic elements related to this factor, approximately have high values. Also, the temperature factor has a positive score but is very low (+0.07) and this indicates that all of the climatic elements associated with this factor have increasing values in this area and include tropical regions. And considering 
that the average annual temperature in this area is 18.710 C, it is considered "hot" in terms of temperature Also, since that the factors of warm-season rainfall and cold season rainfall had a negative score and the average annual rainfall in this area is $103.9 \mathrm{~mm}$, this zone was named: "very arid and warm" the most important vegetation species Which are predominant in these harsh climatic conditions are: Ptropyrum aucheri, Calligonum stenopterum, Artemisia sieberi, Hammada salicornica, Seidlitzia rosmarinus.

\subsubsection{Bio-climatic zone (20) "very arid, warm, windy and dusty"}

This Bio-Climatic zone has an area of 4,812,702 ha and most part of this zone is located in southeastern Iran and also some patches of this Bio-Climatic zone are observed in the centers of Yazd and Isfahan provinces (Fig. 16). The above sea level elevation of this vegetative zone is 1344/46 $\mathrm{m}$ based on the factor scores table, it can be noticed that in this area, the score of temperature factor is positive, but its value is very small $(+0.12)$. This indicates that in this area, the climatic elements associated with this factor have relatively high values and from thermal characteristics, create a warm region. Also in this area, the values of climatic elements related to the warm season rainfall are high and increasing (compared to the neighboring areas). In addition, the wind speed factor has achieved a positive and approximately high score $(+0.67)$. This shows which all the values of climatic elements related to this factor are high in this area and have an increasing trend in this region. Also, the dust factor has a positive score and its value is very high, the dust factor has a positive score and its value is very high, on the other hand, all climatic elements related to factors of snow, thunder, semi-cloudy days, relative humidity and cold season rainfall have small and low values, which indicates these five factors are not apparent and they are not effective on vegetation in this area, also do not have any role in forming and naming of this bioclimatic zone. Therefore according to the above explanations and the high appearance of wind speed and dust factors, as well as the high weight of the two factors of temperature and warm-season rainfall, and also since that the average annual rainfall in this zone is $97 \mathrm{~mm}$, this climatic zone was named: "very arid, warm, windy and dusty". The most important vegetation species which are predominant in these harsh climatic conditions are: Seidlitzia rosmarinus, Salsola tetragona, Artemisia sieberi, Fortuynia bungei, Acanthophyllum glandulosum.

\subsubsection{Bio-climatic zone (21) "arid, cold and windy"}

The aforementioned bioclimatic zone by an area of $8,282,373$ ha and an above sea level elevation of $10 / 1931$ $\mathrm{m}$ is located in the central and eastern regions of Iran (Fig. 16). According to the data of Table 6, it is noticed that in this zone, the temperature factor has a negative and approximately high score $(-0.83)$ suggesting that this area includes cold regions, also living organisms in this Bio-Climatic zone, especially vegetation is adapted to the cold conditions prevailing in this area, also, the two factors of warm-season rainfall and wind speed have obtained positive scores, in this zone and this indicates that all climatic elements which related to these factors include high values and these two factors along with the temperature factor have a higher appearance in this area and plays an effective role in the formation of this Bio-Climatic zone. On the other hand and according to the results of Table 6 it can be seen that the factors of relative humidity, cold season rainfall, dust, semi-cloudy days, snow, and thunderstorms have a negative score, which means that all climatic elements which associated to these 6 factors, have small values and do not have a high appearance in this area. With the above explanations and considering that the average annual rainfall in this zone is $124.85 \mathrm{~mm}$, finally this zone was named "cold, warm and windy". The most important predominant vegetation species in this area are the following types: Artemisia sieberi, Salsola tommentosa, Zygophyllum atriplicoides, Seidlitzia cinera, and phragmites australis.

\subsubsection{Bio-climatic zone (22) "arid and ultra-warm"}

As a whole, this Bio-Climatic zone, with an above sea level elevation of $1169 \mathrm{~m}$ and an area of 3,97,717 ha, includes the southern regions of Kerman and Hormozgan provinces in the south of Iran (Fig. 16). According to the table of factor scores (Table 6) in this area and as can be seen, the score of temperature and relative humidity factors is positive. And this indicates that all of the climatic elements related to these factors include high values also, because it is located in the vicinity of large water resources (the Persian Gulf and Oman Sea), and due to the very high temperature and combination with high relative humidity, ultimately a sultry and unbearable air is created in this bioclimatic zone. On the other hand, the factors of warm-season rainfall, cold season rainfall, and snow have a negative score in this area and all climatic elements associated with these factors have very low and insignificant values thus, in terms of precipitation, this climatic zone has not desired conditions. Also, according to the data in the Table 6 the factors of wind speed, semi-cloudy days, dust and thunder have a negative score, and this shows that in this zone, climatic elements which related to these factors have insignificant very small values. Therefore, according to the above explanations and since the average annual rainfall in this area is $191.66 \mathrm{~mm}$, this zone was called "very 


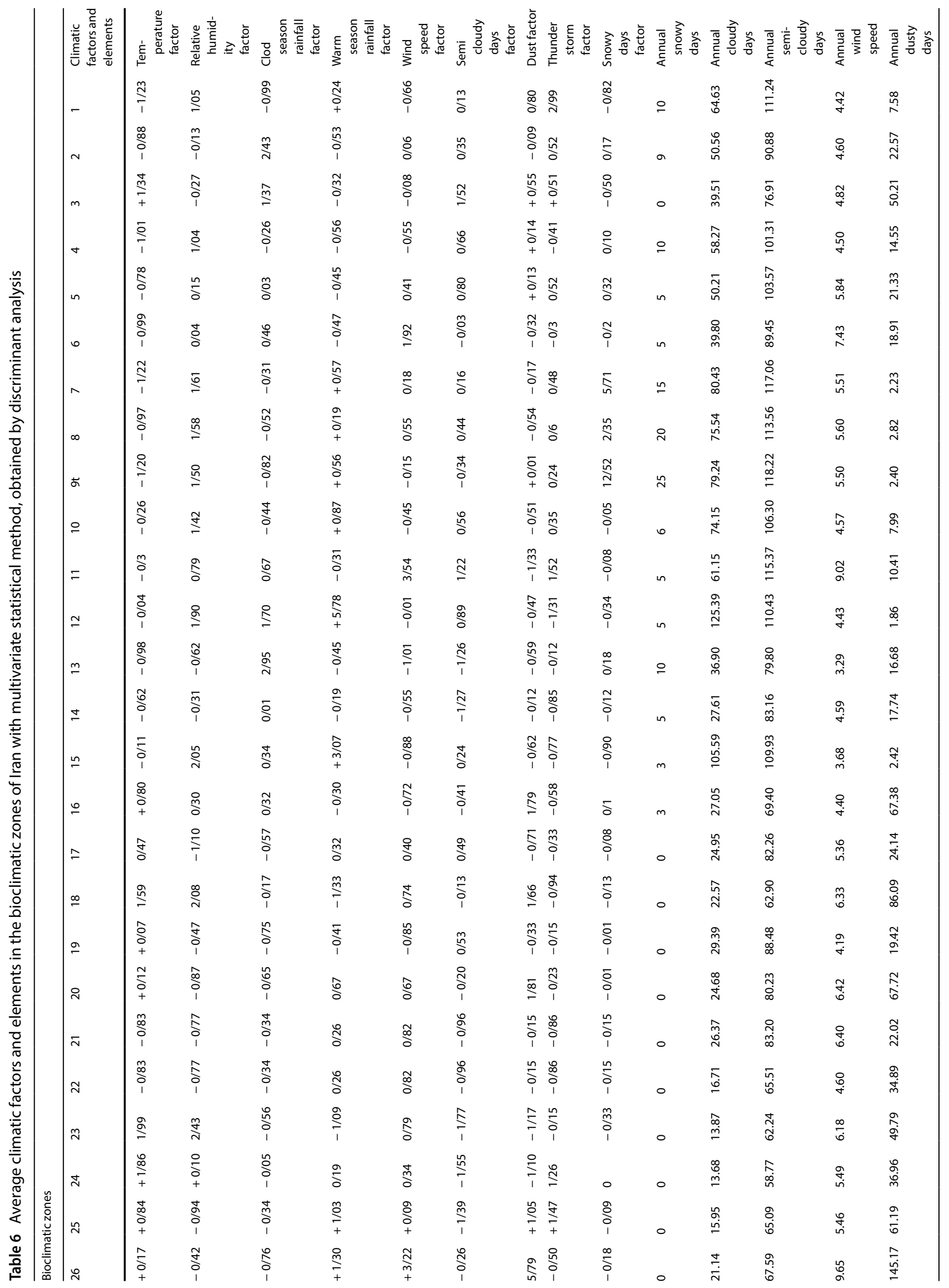




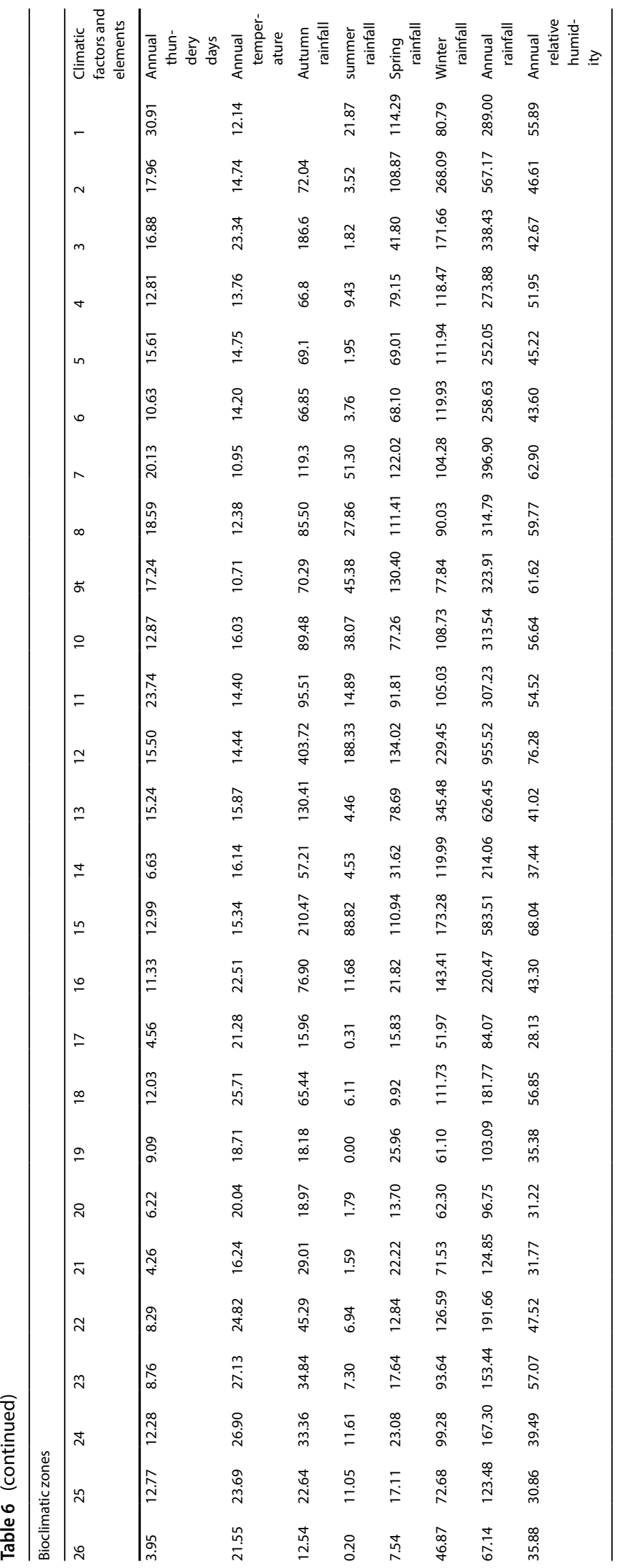


hot and dry". The most important predominant vegetation species in this area are the following vegetation's: Gaillonia aucheri, Cymbopogon Olivieri, Taverniera glabra, Convolvulus leiocalycinus.

\subsubsection{Bio-climatic zone (23) "arid, ultra-warm, windy with high relative humidity"}

This Bio-Climatic zone by an area of $3,288,876$ ha and adjoining to zones of 22 and 18 is located on the outskirts of the Persian Gulf and the Oman Sea (Fig. 16). The above sea level elevation of this zone is $265 / 20 \mathrm{~m}$. According to the factor scores table (Table 6), in this zone, the temperature factor has a very high value and positive score $(+1.99)$. This indicates that all values of climatic elements related to this factor have high values in this zone. And since simultaneous with the high temperature in this zone, the relative humidity factor has, too positive score and its value is very high (2.43), it means that in this zone all of the values of climatic elements associated to this factor have very high values, and thermally, create a sultry air that is very severe warm. In addition, due to the negative score related to warm and cold seasons rainfall factors as well as snow factor, this climatic zone has little rainfall and precipitation. Also, the factors of dust, thunderstorm and semi-cloudy days, too have a negative factor score (according to the data in Table 6) and do not have a high appearance in this area, therefore, they do not have any role in the creation of this Bio-Climatic zone. Meanwhile, the wind speed factor in this zone has a positive and upward score $(+0.79)$ and this shows that the amount of climatic elements related to the wind speed factor is high and this factor, have a high appearance in this zone and along with the relative humidity and temperature factors, have an effective role in the formation of this Bio-Climatic zone. According to the above explanations and since the average annual rainfall in this area is $153.444 \mathrm{~mm}$, this zone was named as "arid, ultra-warm, and windy with high relative humidity ". The most important vegetation species prevalent in this area are the following species: Hammada salicornica, Gymnocarpus decander, Taverniera spartea, Tephrosia apollina.

\subsubsection{Bio-climatic zone (24) "arid, ultra-warm, thundery with relatively windy"}

As it can be seen, Bio-Climatic zone has an area 4,892,552 ha, nestled over in the southern regions of Iran and is attached to zones 22 and 23 . Figure 16. The above sea level elevation of this zone is $602.70 \mathrm{~m}$. The results of Table 6 show that in this zone, climatic factors of temperature and relative humidity have a positive factor score, and this indicates that all of the climatic elements associated with these factors are very high and create sultry weather conditions.
Also, climatic factors of cold seasons, semi-cloudy days, snow, and dust in this area, have a negative score and this shows that the values of all climatic elements related to these 4 factors are very low and insignificant and do not have a high appearance in this area. On the other hand, the factor score of warm-season rainfall in this climatic zone is positive. And this shows that this Bio-Climatic zone which affected by Manson climate (imported from India) in warm seasons of the year, in warm seasons, all climatic elements associated with this factor have large amounts, and this factor has a positive score. According to the data in the Table 6, factors of wind speed and thunder in this climatic zone have a positive score and this indicates that these two climatic factors too, have a high appearance in this zone and affect the vegetation cover in this area. Therefore, based on the above explanations and since the average annual precipitation in this area is $167.30 \mathrm{~mm}$, and with the intervention of factors which have a higher appearance in this zone, this Bio-Climatic zone was named " arid, ultra-warm, thundery with relatively windy". And the most dominant vegetation species prevalent in this area are the following species: Hammada salicornica, Salsola arborescence, Taverniera cuneifolia.

\subsubsection{Bio-climatic zone (25) "arid, very warm, dusty and stormy"}

Having above sea level elevation of 1044.51 ha, this zone with a located in the southeastern of Iran and only includes areas in the center of Sistan and Baluchestan province (Fig. 16). Also, the area of this Bio-Climatic zone is $6,044,722$ ha. According to Table 6 , in this Bio-Climatic zone, the temperature factor has a high factor score $(+0.84)$ and this indicates that all climate elements associated with this factor, have high values. And this climatic zone creates a tropical region based on thermal properties, also, in this zone factors of relative humidity, cold season rainfall, semi-cloudy days and snow have a negative factor score, and this indicates that all of the climatic elements which related to these 4 factors include very small and insignificant values and these factors do not have any role information in this climatic zone, unlike of the cold season rainfall factor in this zone, the warm season rainfall factor has a positive score and this shows that in this zone all the values of climatic elements related to the warm season rainfall factor include high values and compared to the cold season rainfall factor, this factor has a high appearance in this climatic zone and has an effective role on the distribution of vegetation in this zone. Also, the factors of wind speed, thunderstorm, and dust have a positive factor score and these 3 factors along with the warm season rainfall factor in this climatic zone have a high appearance and play an important role in the formation of this zone. 
With this explanation, and since the average annual rainfall in this area is 123.48 , this Bio-Climatic zone was named "arid, very warm, dusty and thundery". The most important predominant vegetation species in this Bio-Climatic zone are the following species: Artemisia sieberi, Zygophyllum eurypterum, Convolvolus acanthocladus, and Gymnocarpus decander.

\subsubsection{Bio-climatic zone (26) "very arid, warm with ultra-dusty and ultra-windy"}

Generally, this Bio-Climatic zone is located in the southeastern region of Iran and is bordered with Afghanistan country (Fig. 16). The above sea level elevation of this zone is 477/20 $\mathrm{m}$, which is located in the north of Sistan and Baluchestan province with an area of 1,527,321 ha. This Bio-Climatic zone has the worst climatic conditions among 26 climatic zones in Iran, so that according to the Table 6 in this Bio-Climatic zone, the factor score of temperature is positive and high score and this means that in terms of heat, on average, warm air temperature prevails in this zone and this factor has high appearance in this area and play an important role in the distribution of vegetation species in this vegetative area. In addition, the score of cold seasonal rainfall, snow and relative humidity factors is negative and this means that all climatic elements which associated with these three factors have very small values and do not have a high appearance in this Bio-Climatic zone, also, the score of warm season rainfall factor is positive, which indicates that all climatic elements related to this factor in this Bio-Climatic zone, have almost higher values than the surrounding areas, and this is very important Especially since the cold season rainfall factor in this area has a negative score, which means that the most of rainfall occurs in the summer and spring seasons of the year. Also, according to the data in the above table (Table 6) climatic factors of wind speed and dust have a positive score in this bioclimatic zone and compared to the all of the above zones, this bioclimatic zone has the highest factor scores related to dust and wind speed factors. According to the above explanations and since the average annual precipitation in this climatic zone is $67.14 \mathrm{~mm}$, this zone was named "very arid, warm with ultra-dusty and ultra-windy ". Vegetation cover adaptable with these climatic conditions are: Aeloropus Lagopoides, Suaeda nitraria, Hammada salicornia, Salsola sp, Tamarix aphylla, Haloxylon aphyllum, Haloxylon persicum.

\section{Discussion}

In 1969, Pabout was the first researcher who mapped bioclimatic zones of Iran by which the country was classified into 3 big bioclimatic zones, which these 3 bioclimatic regions are divided into 8 bioclimatic sub-regions (Fig. 15) from the viewpoint that he is the first person and the first effort in this field, it is important and respectable. But the actuality of Iran's bio climate is also very important, and the results of this assessment should be with the least amount of error and the highest percentage of accuracy. Because these results indicate the bio climate classification of a region or a country. And it should be available to researchers as a reliable source and reference, but unfortunately, the Pabout method has many drawbacks and the most important drawback of this method is that it has identified Iran's bio climate only on the basis of one climatic parameter (annual rainfall). While climate is a phenomenon that is formed from the combination of several climatic variables, and as a result of the influence of these several climatic variables in a region, its vegetation is also affected. And another major drawback of Pabout's method is that it has considered very wide climatic ranges for each climate zone which leads to differences, inconsistencies, and inaccuracies in the results of climate classification. For example, in the Pabout method, areas with $200 \mathrm{~mm}$ to $420 \mathrm{~mm}$ of rainfall are named "semi-steppe". That is, the regions in Kurdistan province in western of Iran with an average annual rainfall of $400 \mathrm{~mm}$, with the regions in Fars province in southern Iran with a rainfall of $200 \mathrm{~mm}$ as a climate named "semi-steppe" (according to Fig. 15). While in an area where the rainfall is $200 \mathrm{~mm}$, the type of vegetation cover, density, and also the percentage of vegetation cover is different from the areas where the rainfall is twice as much as $400 \mathrm{~mm}$ [17]. Pabout defines areas with less than $100 \mathrm{~mm}$ of annual rainfall under a "semi-desert" climate, and that's just enough in this method, which the semi-desert climate has a maximum annual rainfall of $100 \mathrm{~mm}$, and as can be seen according to Pabout Map (Fig. 15), the "semi-desert" climate is located in the center of Iran and includes some parts of Isfahan, Semnan, Yazd, Kerman, and Sistan \& Baluchestan provinces. However, when the precise rainfall of these areas was examined by multivariate statistical methods, it was cleared that this climatic zone has some problems (drawbacks). So that the areas in South Khorasan province (in the south and center of this province) which are in the form of cylindrical bars have an annual rainfall of more than $100 \mathrm{~mm}$ and it should not be in this climatic range, and contradicts by the definition of the Pabout method in the semi-desert range, and certainly the area with the highest annual rainfall is different of the type and the density of vegetation [16] Another explicit problem with the "semi-desert" zone in the Pabout method is the heterogeneity of climatic factors in the different parts of this zone, so that in the eastern parts of this zone, the two climatic factors of dust and wind speed have the highest intensity and amount compared to other parts of this region, and in other parts of this region, the climatic 
elements which associated with these factors, have very low intensity, and unfortunately the Pabout method did not mention to this heterogeneity of climatic factors, and the impact of these important factors has been ignored. While this zone (semi-desert climatic zone, in pabout method) has been divided into 4 bio-climatic zones into multivariate statistical methods (zones of 17, 19, 20, and 26) and has been accounted for for exactly the effect of climatic factors on the creation of Bio-Climatic zones. For example, Sistan region in the north of Sistan \& baluchestan province has the highest amount of dust and wind speed in Iran and the vegetation characteristics of this region are very dry and with very low density and certainly, these characteristics are due to the high amount of wind speed and dust in this area. Also, the vegetation in this area is salty and the morphological characteristics of this vegetation are adaptable with this climate.

Another important weakness to the traditional Pabout method is that, if the semi-desert climate is generally discussed in this method, according to the definitions of the meaning and concept of semi-desert and desert climatic zones, in the Pabout method, these two concepts are not well separated. For example, areas in the north of Sistan \& Baluchestan province (in southeastern of Iran), areas in the east and northeast of Kerman province (approximately in the center of Iran), eastern and northeastern regions of Isfahan and Yazd provinces (in the center of Iran) Based on the climate reality, that is predominant in these parts of Iran, these areas have" desert" climates. While, in the Pabout method, these areas are classified as "semi-desert" climates, and this dichotomy in the concept of climate in a region or zone is one of the main weaknesses and drawbacks of this method. Also, in the pabout method, the areas that are considered "steppe climate" has main and basic drawbacks. Because firstly, a large area of Iran with bio- climatic heterogeneity allocated to this climatic zone. As seen, from the western regions of Iran in Khuzestan province to parts of the south of Iran and near the shores of the Persian Gulf and the Oman Sea, with areas in eastern and northeastern of Iran, has been named under this climate and Second, areas with 100 to $300 \mathrm{~mm}$ of rainfall are named under this climate. That is, an area that receives $100 \mathrm{~mm}$ of annual rainfall is similar in climate to an area that receives $300 \mathrm{~mm}$ of annual rainfall. As can be seen, the amount of rainfall in the second zone is triple as much as the rainfall in the first zone, and as accounted for in the description of the "semi-steppe" zone, in the area where the rainfall is $300 \mathrm{~mm}$, the type of vegetation cover, species diversity and richness, density and percentage of vegetation cover are different from areas with less rainfall. And the characteristics of the vegetation species in this area will also be affected, and as will be seen in the following sections, we will see different species and even different vegetation varieties in the two regions While Pabout has considered the same these areas. Due to the fact that multivariate statistical methods based on computer and accurate methods in all regions of Iran identified climatic factors that affected vegetation's, and when these results are compared to the Pabout method, the weaknesses of the Pabout method be more apparent. As in the western regions of "steppe zone" which includes parts of Khuzestan province and also areas in Fars province in the south of this zone, the climatic factor of "dust" has a relatively high appearance and is one of the main effective and important climatic factors in the distribution of vegetation types and creation of a climate in this area. Or the wind speed factor in the eastern regions of this zone has a high appearance Also, the Thunderstorm factor only has a high appearance in the southern regions of Sistan \& Baluchestan province, which are located in the "steppe" zone, and in other areas of this zone, this climatic factor does not have a high appearance. Another example in this regard, is the spatial distribution of relative humidity in this zone, So that the southern regions of this zone, which are close to the shores of the Persian Gulf and the Oman Sea, have a very high appearance of relative humidity factor and other regions of this zone have the low appearance of relative humidity factor. As can be seen, these problems are in the "stepp" climatic zone of the Pabout method, and unfortunately, despite the heterogeneity in the spatial distribution of climatic factors in different parts of this zone, all of this area, considered as "steppe climate". However, in multivariate statistical methods, these differences are correctly considered. On the other hand, as can be seen in Fig. 15, each of the climatic zones in the Pabout method includes several zones in the multivariate statistical methods. For example, the range of arid forests (in the Pabout method) is divided into 11 bio-climatic zones into the multivariate statistical methods, which consists of a special vegetation cover. The area where Pabout has separated under the climatic zone of arid forests, includes predominant vegetation species that do not determine the specific climatic zone of these genus, species, and even vegetation varieties. Rather, unfortunately, placed all of them in a wide range of areas named "arid forests." but, in the multivariate statistical methods, each of these dominant species separated based on the climatic zone of each region and belongs to a specific climatic zone. In this regards, the genus of Astragalus has different species and varieties which any species or a variety of this genus is distributed in a particular climate and their Bio-Climatic zones must be separated, while this has not been done in pabout method and placed several different species of Astragalus genus in an area which named the "Arid Forests" zones. For example, Astragalus Angustiflorous species is distributed in the northwestern of Iran and in the western regions of West Azerbaijan 
province that in the Pabout method, this area includes the climatic zone of "arid forests", but in the multivariate statistical methods, this species is distributed in the bioclimatic zone of "medium semi-arid, very cold and ultrathundery". As can be seen, the difference between the two methods of Pabout and the multivariate statistical methods in separating of the Bio-Climatic classification of Iran is apparent, so that according to the multivariate statistical methods, the climatic zone of this vegetation species was determined "medium semi-arid, very cold and ultra-thundery". And climatic conditions that require for distribution of this species are: The factor score of temperature in the distribution area of this vegetation species is, $-1 / 10$, that means in this area, all of the climatic elements associated with this factor have low values and include very cold regions. On the other hand, another species of Astragalus, scientifically known as As.Caryolobous, is distributed in western Iran and in the northern regions of Kurdistan province which, in the Pabout method, these areas are located in the climatic zones of "arid forests" but, in the multivariate statistical methods, As. Caryolobous vegetation type is distributed in the climatic zone of "humid, very cold and thundery". That is the suitable climatic conditions for the distribution of the As.Caryolobous types are: the factor score of temperature is -1.36 , which means, the optimal thermal conditions for the distribution of this species of Astragalus are very cold conditions. So that the annual temperature in the distribution areas of this species is $11.480 \mathrm{C}$, also, the relative humidity factor score is +0.62 , which means that in terms of relative humidity, these areas have desirable conditions for this species. So that, the percentage of annual relative humidity in these areas is $52.72 \%$. The factor score of the cold season rainfall is +1.89 . Which means, the As.Caryolobous vegetation type are more dependent on the rainfall of the cold seasons, so that the amounts of rainfall in the cold and warm seasons of the year in the distribution areas of this species are 23/424 mm and $153 \mathrm{~mm}$ respectively, as can be seen, compared to the previous species of Astragalus, the need for rainfall in this species is much higher and only in the multivariate statistical methods, these differences are mentioned but unfortunately in the Pabout method these differences are not mentioned. Also, the factor score of wind speed in the distribution areas of this species is -0.3 , which means that the wind speed is very low, so that the annual wind speed in these areas is 4.11 knots. The factor score of the dust is negative, naming that the number of annual dust days in this area is few days ( 13 days in annual) and these two climatic factors of wind speed and dust do not have any role in distribution of this vegetation species in this area Also the factor score of thunder storm in the distribution areas of As.Caryolobous vegetation type is +0.09 , that is, compared to other climatic regions of Iran, it is relatively high and has an effective role in the distribution of this species, so that the number of annual thunder days in the distribution areas of this species of Astragalus is 15 days. Another species of Astragalus, scientifically named As.Caraganae, is distributed in the western regions of the Caspian Sea and is close to the Caspian region which the distribution areas of this species by Pabout method located in the "Arid Forests" area but this areas which containing of As.Caraganae vegetation species are located in the climatic zone of "semi humid, very cold, thundery and relatively snowy" by the multivariate statistical methods. So that the suitable climatic conditions for the distribution and growth of As.Caraganae in Iran are: The factor score of temperature is -1.54 , which means that from thermally viewpoint, distributed in very cold conditions and the optimal temperature conditions for this species are the average annual temperature is $10.38^{\circ} \mathrm{C}$, the average of maximum annual temperature is $16.30{ }^{\circ} \mathrm{C}$, the average of minimum annual temperature is $+4.24{ }^{\circ} \mathrm{C}$, the average annual relative humidity is $52 \%$, the average annual wind speed is 5.21 knots, the number of days with annual dust are also 4 days, the number of days with Thunder are 31 days, the average rainfall of the cold and warm seasons are $135 \mathrm{~mm}$, and $152 \mathrm{~mm}$ respectively, also the annual snowy days are 9 days compared to other climatic regions in the distribution areas As.Caraganae vegetation species.

Another species of Astragalus, scientifically named As. rawlinsianus and distributed in the northeastern of Iran and the areas of Golestan province, located in the "Arid Forests" area by Pabout method but these areas which containing As. rawlinsianus vegetation species are located in the climatic zone of "semi humid and cold" So that the suitable climatic conditions for the distribution and growth of As. rawlinsianus in Iran are: The average annual temperature is $14^{\circ} \mathrm{C}$, the maximum and minimum annual temperatures are 20.33 and $7.80^{\circ} \mathrm{C}$ respectively, also, the moisture requirement for of this species in this area is: the average annual relative humidity is $62.5 \%$, the average cold season rainfall is $274 \mathrm{~mm}$ and the average warm-season rainfall is $160 \mathrm{~mm}$, which are more dependent on the cold season's rainfall, the average annual wind speed is 4.43 knots, the number of days with annual dust is 9 days and also, the number of annual thunderstorms are 11 days in this areas.

A species of Astragalus with the scientific name As. managetta, which is distributed by the Pabout method in the climatic zone of "arid forests" and in the multivariate statistical methods, it belongs to Bio-Climatic zone of 13 which named "humid, very cold and relatively snowy" zone and grows in conditions that are: The average annual temperature is $15.5^{\circ} \mathrm{C}$, the maximum and minimum annual temperatures are 20.75 and $6{ }^{\circ} \mathrm{C}$ respectively, that the 
optimal thermal conditions for the growth and distribution of this species of Astragalus are very cold conditions. Also, the average annual relative humidity for this species is $42.6 \%$. The average rainfall of cold seasons is $706 \mathrm{~mm}$ and the average rainfall of warm seasons is $114 \mathrm{~mm}$, which is more dependent on the rainfall of cold seasons. The average annual wind speed is 2.95 knots, the number of days with annual dust is 11 days and also, the number of annual thunderstorms is 18 days in these areas. As can be seen, all of these species of Astragalus grow and distribution in different climatic conditions and the needs of the elements and climatic factors of each Astragalus species are different from the other species, so that if each of these species is established in another climate, the solidification of vegetation and their growth will be difficult, that Unfortunately in the Pabout method, these differences in the climatic factors and elements required for the distribution of the various species of Astragalus mentioned above are not indicated and has placed all of the above Astragalus species under a climate named the "Arid forest" zone while, as can be seen, and according to the multivariate statistical methods, any Astragalus species has different climatic characteristics and each of the Astragalus species belongs to a different Bio-Climatic zone.

These defects and errors are also seen in the "semisteppe" zone. In the Pabout method, this zone includes large areas of Iran, so that the climate of these areas is different. And in each climate, the indicator vegetation species and specific to each area grow and distribute which have different ecological and climatic needs.

For example, a species of Bromus, scientifically known as Bromus danthoniae, is distributed in the southern regions of East Azerbaijan Province and is one of the indicator species in this area of Iran. Which from climatic needs, it is adaptable and limited to this region of Iran and the varieties of this species have adapted to the climatic condition in this region of Iran. And Pabout's method considers the Bio-Climatic zone of this species to be "semisteppe" zone, and unfortunately, the climatic-ecological needs of this species have not been accurately determined. Rather, this method, generally mentions conditions that do not accurately reflect the dominant climatic conditions of any vegetation species or species. However, in the multivariate statistical method, the predominant climate on the distribution of Bromus danthoniae has been named "moderate semi-arid, very cold, ultra-thundery". Naming that this species of Bromus from thermally distributed in conditions where these areas have an average temperature factor score of -1.23 , this means that the optimal temperature conditions for the distribution of this species of Bromus are very cold temperatures, as The average annual temperature for Bromus danthoniae is $12.14^{\circ} \mathrm{C}$, also, the average maximum annual temperature is $18^{\circ} \mathrm{C}$ and the average minimum annual temperature is $6{ }^{\circ} \mathrm{C}$. Also, the factor score of relative humidity in the distribution area of Bromus danthoniae is +0.05 , which indicates that this vegetation species needs high relative humidity to survive and distribution and adaptable with the high percentage of relative humidity that predominates in this climatic zone. As the average percentage of suitable relative humidity in this area for the distribution, of the above species is $55.89 \%$. Also, the average rainfall of warm seasons for this species in this area is $153 \mathrm{~mm}$ and the average rainfall of cold seasons is $136 \mathrm{~mm}$. The average annual wind speed in these areas is 4.42 knots, the number of days with annual dust is 8 days, and the number of days with annual thunder is 37 days per year. In general, the suitable climatic conditions for the growth and distribution of Bromus danthoniae were mentioned and these climatic conditions must be provided So that the above vegetation species can complete its growth and distribution.

Now a species of Bromus, scientifically known as Bromus tectorum, is referred, which according to the Pabout method, is also distributed in the "semi-steppe" Bio-Climatic zone with the previous species, but, according to the multivariate statistical methods, this species of Bromus is distributed in western of Iran and in bio-climatic zone 2 , named "humid, very cold and relatively thundery" zone. As the name implies, this zone thermally includes very cold regions and this vegetation species is present in an area with an average annual temperature of $14.5^{\circ} \mathrm{C}$ also, the maximum and minimum annual temperature in the distribution area of this species is 21.71 and $7.75{ }^{\circ} \mathrm{C}$, respectively. Also, the average annual relative humidity in this region is $46.61 \%$, the average rainfall of cold seasons for this species of Bromus is $455 \mathrm{~mm}$ and the average rainfall of warm seasons is $113 \mathrm{~mm}$. And this species depends more on the cold season's rainfall. Also, in the distribution area of this species, the average annual wind speed is 4.60 knots and the number of days with annual dust is 23 days. The number of days with annual thunder is 18 days. As can be seen, the all of the climatic characteristics required for the growth and distribution of this Bromus species are different from the climatic characteristics required for the growth and evolvement of the previous species. Another species of Bromus, scientifically known as Bromus Sterlis, which according to the Pabout's method has been identified as a "semi-steppe" distribution area, along with the two previous species of Bromus. But, according to the multivariate statistical methods, this species of Bromus is distributed in southwestern Iran and in the bio-climatic zone of (3), naming "semi-humid, very warm, relatively thundery and relatively dusty". As the name implies, this species of Bromus is thermally distributed in very warm conditions. As the average annual temperature and desirable 
for this species of Bromus is $23.34{ }^{\circ} \mathrm{C}$. Also, the average maximum and minimum annual temperature suitable for this species are 30.64 and $16.05^{\circ}$, respectively. The average annual relative humidity is $42.67 \%$, the average cold season rainfall is $297 \mathrm{~mm}$ and the average warm-season rainfall is $44 \mathrm{~mm}$, which significantly dependent on the cold season's rainfall. Also, in the bio-climatic zone of this species, the average annual wind speed is 4.82 knots and the number of days with annual dust and thunder is 50 and 17 days, respectively. All of the climatic characteristics required for the growth of this species of Bromus are unique and are quite different from the needs of the climatic elements and factors required for distribution and growth with the previous species. Especially since this species is located in a very warm environment and almost close to the shores of the Persian Gulf and the Oman Sea, and is also exposed to soil and sandstorms that occur both in the region itself and enter the region from the border with Iraq. There is also a species of Bromus with the scientific name of Bromus tomentellus, which according to Pabout method, the climatic zone of this vegetation species with three previous species has been considered as "semi-steppe" zone. But, in multivariate statistical methods, it is approximately distributed in the central regions of Iran and in the bio-climatic zone of "semi-arid and cold" zone. This zone thermally is cold and the average annual temperature and suitable for growth and distribution of this species is $16.14{ }^{\circ} \mathrm{C}$, also the maximum and minimum annual temperatures and optimal for this species of Bromus are 23.48 and 8.80 degree Celsius, respectively. Also, the average annual relative humidity for the growth and evolvement of this species of Bromus tomentellus is $37 \%$, which has a lower relative humidity percentage than the previous three species because it is located in a drier area. The average rainfall of cold and warm seasons is $117 / 20$ and $36.15 \mathrm{~mm}$, respectively, and is strongly dependent on the cold season's rainfall, also in this distribution area the average annual wind speed is 4.95 knots and the number of days with annual dust is 18 days. As can be seen, four types of Bromus have been introduced that have completely different needs of climatic characteristics and are distributed in completely different bio-climatic zones and environments, unfortunately, despite these differences, Pabout's method has named these species "semi-steppe" climates. While the multivariate statistical methods separate each of these species according to the type of climatic need, in a segregate climate, and exactly specific to each of the vegetation species. Various vegetation species of "Bromus" as an example of the "semi-steppe" zone and different vegetation species of "Astragalus" as an example of the "arid forests" mentioned in the previous section are examples of incorrect zoning of the Pabout method, but multivariate statistical methods knowing that climate is a phenomenon composed of several climatic elements and considering the obvious and influential climatic factors in each of climatic zone, the bio-climatic zonation of Iran has been separated in such a way that each of bio- climatic zone has its own unique characteristics in the distribution and growth of vegetation species. On the other hand, species and even vegetation varieties in each bio-climate zone are separated according to their specific traits.

\section{Concluding remarks}

Investigation of Iranian vegetation implies that the bio-climatic zones separated in the multivariate statistical methods correspond with the dominant vegetation species in each zone. In any climatic zone, adaptable vegetation species are distributed within that climate. Given such explanations, the fact that multivariate statistical methods are effective in separating of bio-climatic classification is more apparent. As well, such efficiency of multivariate statistical methods has been confirmed by a large number of climatologists in comparison with the traditional methods of bio-climatic classification $[1,15]$. Iran is characterized by a special climate in different parts of the country, which is dominated by different climatic phenomena in different parts of Iran. For example, the climatic factor of wind in the eastern, southeastern, northern (Manjil and Rudbar) and southwestern regions of Iran is one of the main climatic factors in the formation of climate in these regions. Also, special climatic phenomena such as thunder, in the northwestern regions (East and West Azerbaijan) and the southeast (south of Sistan and Baluchestan province) are considered as the main factors forming the climate in these areas. Or the climatic factor of dust in the eastern regions of Iran, as well as the southern and southeastern regions of Iran, are effective in the distribution of vegetation in these regions and ultimately affect the climate of these regions.

With this introduction and these explanations, these climatic factors have not been used in any of the traditional methods of dividing the bio- climatic zones of Iran (especially Pabout method) and conversely, in most traditional methods, only the two factors of temperature and rainfall are used in the classification of bio-climatic zones, so their results are not very accurate. Therefore, their results are not very accurate and have many drawbacks and do not correspond with the vegetation covered in the separated climates. On the other hand, the basis and criteria defined for the range of bio-climatic zones do not correspond to each other by the pabout method and are completely different from each other. While, in the multivariate statistical methods, all defined ranges for bio-climatic zones are separated based on the intensity and amount of climatic factors obtained in each climatic zone. 
Finally, here are some of the advantages of a multivariate statistical methods:

1. They have the potential to use a large number of climate variables and it has more in common with the definition of climate, as a complex phenomenon and since one or more elements are usually dominant in each area, they clearly form the area. These methods make it possible to identify these elements.

2. They have the potential to summarize a lot of climatic data without losing much of the information.

3. These methods enable the researcher to better visualize and interpret data more easily

4. These methods enable the simultaneous analysis of a large set of data.

5. These methods provide a convenient way to handle a set of multi-variable data.

6. These methods provide an accurate reflection of multidimensional and multivariate systems.

7. These methods provide a good formula and suitable principles for integrating variables.

8. They allow identify and quantify real multi-variable patterns that arise from the correlation structure of a set of variables.

9. They have the potential to use the latest scientific achievements related to mapping and statistical methods in multivariate methods.

\section{Compliance with ethical standards}

Conflict of interest The authors declare that they have no competing interests.

\section{References}

1. Ahmed BYM (1997) Climatic classification of Saudi Arabia: an application of factor-cluster analysis. GeoJournal 41(1):69-84

2. Amigo J, Ramirez C (1998) A bioclimatic classification of Chile: woodland communities in the temperate zone. Plant Ecol 136(1):9-26

3. Brown A, Birks HJB, Thompson DBA (1993) A new bio geographical classification of the Scottish uplands. II. Vegetation-environment relationships. J Ecol 81:231-251

4. Carey PD, Preston C, Hill MO, Usher M, Wright S (1995) An environmentally defined bio geographical zonation of Scotland designed to reflect species distributions. J Ecol 83:833-845

5. Farshadfar A (2010) Multivariate statistical principles and methods. Razi University Press, Cyberjaya

6. Gavilan RG (2005) The use of climatic parameters and indices in vegetation distribution. A case study in the Spanish Sistema Central. Int J Biometeorol 50(2):111-120

7. Gould WA, Walker DA, Biesboer D (2003) Combining research and education: bioclimatic zonation along a canadian arctic transect. Arctic 56(1):45-54
8. Hill MO (1991) Patterns of species distribution in Britain elucidated by canonical correspondence analysis. J Biogeogr 18:247-255

9. Hossell JE, Riding AE, Brown I (2003) The creation and characterization of a bioclimatic classification for Britain and Ireland. J Nat Conserve 11:5-13

10. IPCC (2001) Climate change. 2001.The scientific basis summary for policy makers. Shanghai draft (21/01/01). Intergovernmental panel on climate change. Cambridge Academic Press, Cambridge

11. Junior A, Carvalho LG, Silva FF, Marcelo CA (2011) Application of the Koppen classification for climatic zoning in the state of Minas Gerias, Brazil. Theoret Appl Climatol 108(1-2):1-7

12. Leilei $L$, Jianrong $F$, Chen $Y$ (2014) The relationship analysis of vegetation cover, rainfall and land surface temperature based on remote sensing in Tibet, China. In: 35th international symposium on remote sensing of environment (ISRSE35) IOP publishing IOP conferences series: earth and environmental science

13. Malmgren BA (2010) Climate zonation in Puerto Rico based on principal components analysis and an artificial neural network

14. Martinez LF, Carbajal NE, Medina-Roldan E (2006) Regionalization and classification of bioclimatic zones in the central-northeastern region of México using principal component analysis (PCA). Atmósfera 20(2):133-145

15. Martinez LFP, Carbajal N (2017) Climatic analysis linked to land vegetation cover of Mexico by applying multivariate statistical and clustering analysis. Atmósfera 30(3):233-242

16. Mesdaghi M (2005) Applied ecology. Mashhad University Jihad Publications, Mashhad

17. Moghadam M (2005) Ecology of soil plants. University of Tehran Press, Tehran

18. Netzel P, Tomasz S (2016) On using a clustering approach for global climate classification. J Clim 29(9):3387-3401

19. Pabout $H$ (1969) Development and improvement of rangelands through botanic and ecological studies. Publications of Forests and Rangelands Organization

20. Pienkowski MW, Bignal EM, Galbraith CA, McCracken DI, Stillman RA, Boobyer MG (1996) A simplified classification of land-type zones to assist the integration of biodiversity objectives in landuse policies. Biol Cons 75(1):11-25

21. Pesaresi S, Galdenzi D, Biondi E, Simona C (2014) Bio climate of Italy: application of the worldwide bioclimatic classification system. J Maps 10(4):538-553

22. Retueto R, Carballeira R (1992) A Use of direct gradient analysis to study the climate vegetation relationships in Galicia, Spain. Plan Ecol 101(2):183-194

23. Rosati B, Fioria M, Motronia A, Filigheddub F, Emmanuele $F$ (2015) Bio climate map of Sardinia (Italy). J Maps 11(5):711-718

24. Schmidt M, Klein D, Conrad Ch, Christopher D, Dech S, Heiko $S$ (2014) On the relationship between vegetation and climate in tropical and northern Africa. Theoret Appl Climatol 115(1):341-353

25. Sneath PHA, Sokal RR (1973) Numerical taxonomy: the principles and practice of numerical classification. Freeman, San Francisco, p 573

26. Singh MK, Mahapatra S, Atreya SK (2007) Development of bioclimatic zones in north-east India. Energy Build 39:1250-1257

27. Stiner D (1965) A multivariate statistical approach to climatic classification; Tidschriftvan het Koninklijk Nederland's. Aardrijkskunding. Genootschap 82:329-347

28. Tsemma ZK, Wei Y, Peel MC, Western AW (2014) Including the dynamic relationship between climatic variables and leaf area index in a hydrological model to improve stream flow prediction under a changing climate. Hydrol Earth Syst Sci 19:2821-2836 
29. Wang T, Hermann A Spittle, House D, Murdock TQ (2012) Climate WNA-high-resolution spatial climate data for Western North America. Am J Climatol 51:16-29

30. Ward JH Jr (1963) Hierarchical grouping to optimize an objective function. J Am Stat Assoc 58:236-244

31. White EJ (1981) Classification of climate in Britain. J Environ Manag 13:241-258

32. Xu JN (2013) The relationship between vegetation coverage and climate elements in Yellow River Basin, China Qin. Peer J Prepr 1:e153v1
33. Zhou D, Khan SH, Abbas A, Rana T, Zhang H, Yun CH (2009) Climatic regionalization mapping of the Murrumbidgee Irrigation Area, Australia. Prog Nat Sci 19:1773-1779

Publisher's Note Springer Nature remains neutral with regard to jurisdictional claims in published maps and institutional affiliations. 